\title{
Toxoplasma gondii ROP18 inhibits human glioblastoma cell apoptosis through a mitochondrial pathway by targeting host cell P2X1
}

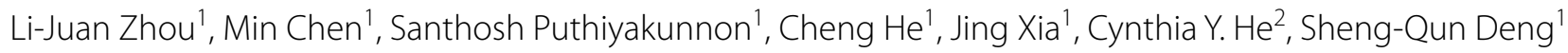
and Hong-Juan Peng ${ }^{1 *}$

\begin{abstract}
Background: Apoptosis plays a critical role in the embryonic development, homeostasis of immune system and host defense against intracellular microbial pathogens. Infection by the obligate intracellular pathogen Toxoplasma gondii can both inhibit and induce host cell apoptosis; however, the parasitic factors involved remain unclear. The T. gondii virulence factor ROP18 (TgROP18) has been reported to regulate host cell apoptosis; nevertheless, results for this regulation have been rarely reported or have provided contradictory findings. Human purinergic receptor 1 (P2X1) is an ATP-gated ion channel that responds to ATP stimulation and functions in cell apoptosis mediation. The precise roles of TgROP18 in T. gondii pathogenesis, and the relationship between TgROP18 and host P2X1 in host cell apoptosis are yet to be revealed.

Methods: Apoptosis rates were determined by flow cytometry (FCM) and TUNEL assay. The interaction between TgROP18 and the host P2X1 was measured by fluorescence resonance energy transfer (FRET) and co-immunoprecipitation (co-IP) assay. Calcium influx and mitochondrial membrane depolarization were determined by FCM after JC-1 staining. The translocation of cytochrome $\mathrm{C}(\mathrm{Cyt} \mathrm{C}), \mathrm{Bax}$ and $\mathrm{BCl} 2$ proteins, expression of the apoptotic proteins PARP and caspase activation were detected by western blotting.

Results: The apoptosis rates of glial or immune cells (human SF268, mouse RAW264.7 and human THP-1 cells) infected by any T. gondii strain (RH-type I, ME49-type II and VEG-type III) were significantly inhibited compared with their uninfected controls. TgROP18 inhibited ATP-induced apoptosis of SF268 with P2X1 expression, but had no effect on RAW264.7 or THP-1 cells without detectable P2X1 expression. It was further identified that TgROP18 interacted with P2X1, and overexpression of ROP18 in COS7 cells significantly inhibited cell apoptosis mediated by P2X1. Moreover, TgROP18 also inhibited P2X1-mediated $\mathrm{Ca}^{2+}$ influx, translocation of cytochrome $\mathrm{C}$ from the mitochondria to the cytosol, and ATP-triggered caspase activation.
\end{abstract}

Conclusions: Toxoplasma gondii infection inhibits ATP-induced host cell apoptosis, regardless of strain virulence and host cell lines. TgROP18 targets the purinergic receptor P2X1 of the SF268 human neural cells and inhibits ATPinduced apoptosis through the mitochondrial pathway, suggesting a sensor role for the host proapoptotic protein $\mathrm{P} 2 \mathrm{X} 1$ in this process.

Keywords: Toxoplasma gondii, ROP18, Mitochondria, Apoptosis, P2X1, ATP

\footnotetext{
${ }^{*}$ Correspondence: floriapeng@hotmail.com

${ }^{1}$ Department of Pathogen Biology, Guangdong Provincial Key Laboratory of Tropical Disease Research, School of Public Health, Southern Medical University, Guangzhou 510515, Guangdong, People's Republic of China Full list of author information is available at the end of the article
} 


\section{Background}

Toxoplasma gondii, an obligate intracellular protozoan, can infect humans and nearly all warm-blooded animals [1]. It is estimated that $30 \%$ of the world human population is infected with T. gondii [2]. Toxoplasma gondii infection shows no or mild symptoms in immune competent hosts; however, the symptoms may be severe in immunocompromised patients and after congenital infections [2]. Based on their acute virulence in the mouse model, $T$. gondii strains are categorized into the highly virulent type I (RH) strain with a lethal dose (LD) of one parasite, and non-virulent type II (ME49, PLK) and type III (CEP) strains with an LD50 of more than 1000 parasites [3, 4].

Toxoplasma gondii infection can both inhibit and induce host cell apoptosis. These opposing effects might involve complicated factors that modulate the finely balanced interaction between the parasite and the proand anti-apoptotic signals of the host, such as the host cell type, the virulence of T. gondii and others [5]. For example, tachyzoites of the $\mathrm{RH}$ strain promote apoptosis of mouse neural stem cells [6], while inhibiting apoptosis of human leukemic, THP-1 and Jurkat cells $[7,8]$. Apoptosis of trophoblast cells can be induced by ME49 infection, whereas it is inhibited by $\mathrm{RH}$ infection [9]. Toxoplasma gondii ROP18 is a Ser/Thr kinase secreted by the rhoptries into the PV and host cytosol during invasion [10]. Among the laboratory strains that infect mice, type I strains avoid the accumulation of host immunity-related GTPases (IRGs) on the parasitophorous vacuole $(\mathrm{PV})$ to protect the parasite from clearance, which is partly attributed to the expression of TgROP18 [11]. TgROP18 can degrade host cell proteins activating transcription factor 6 beta (ATF6 $\beta$ ) or transcription factor $\mathrm{P} 65$ and help the parasite resist the host innate immune response [12, 13]. Moreover, ROP18 has also been reported to induce apoptosis of mouse N2a neural cells [14] and inhibit the apoptosis of the 293T human epithelial cells induced by actinomycin D (act D) [15]. However, the precise roles of TgROP18 and its significance to T. gondii pathogenesis are yet to be established.

Apoptosis can be triggered by either a physiologic or a pathologic stimulus, exhibiting cytoplasmic shrinkage, chromatin condensation, nuclear fragmentation, plasma membrane blebbing, and finally formation of apoptotic bodies which are efficiently absorbed by neighboring cells with phagocytic activity and degraded within lysosomes [16]. It plays a critical role not only in development and homeostasis but also in host defense against microbial infection [17, 18], particularly in clearance of intracellular microbial pathogens [19]. Therefore, for their survival, obligate intracellular pathogens like $T$. gondii have evolved many ways to interfere with the highly regulated host cell apoptotic pathways [20,21].

Both immune response and apoptosis are triggered and regulated by signaling molecules. One of the signaling molecules is adenosine triphosphate (ATP). Inside a cell, ATP serves as a major energy source, whereas outside of the cell, ATP functions as a potent autocrine and paracrine signaling molecule for immune response [22-25]. For example, extracellular ATP can induce apoptosis in the human neuroblastoma cell line SH-SY5Y by decreasing expression of the anti-apoptotic protein $\mathrm{Bcl} 2$ and increasing expression of the proapoptotic protein Bax [26].

ATP signaling is mediated by cell-surface P2 purinergic receptors, which consist of two families of receptors, P2X and P2Y receptors $[24,25]$. The former are cation channels gated by extracellular ATP, and the latter G-protein-coupled metabotropic receptors. P2X receptors are homotrimeric and heterotrimeric proteins assembled from seven types of subunits, P2X1-7 [27]. P2X1 is formed with a trimeric assembly of the subunits with two transmembrane regions, the intracellular amine and the carboxyl-terminal region, and a large extracellular ligand binding loop [28]. P2X1 has also been reported to be phosphorylated at the C-terminus, and a conformational change in $\mathrm{P} 2 \mathrm{X} 1$ is required for coordination of ATP action [29]. Immunohistochemistry and functional studies have shown that P2X1 is expressed predominantly on the membrane of smooth muscle cells, blood cells and neurons [30-32]. P2X1 activation results in cell apoptosis characterized by $\mathrm{Na}^{+}$and $\mathrm{Ca}^{2+}$ influx and $\mathrm{K}^{+}$ efflux, which leads to depolarization of the plasma membrane [32]. The cell apoptosis rate is increased in mouse thymocytes overexpressing $\mathrm{P} 2 \mathrm{X} 1$, indicating that $\mathrm{P} 2 \mathrm{X} 1$ is a proapoptotic protein [33]. Whether $\mathrm{P} 2 \mathrm{X} 1$ is a target protein in the modulation of host cell apoptosis by $T$. gondii is not known.

In this study, we found that $T$. gondii infection inhibited the ATP-induced apoptosis of SF268, THP-1 and RAW264.7 cells, regardless of strain virulence and host cell lines tested. Furthermore, we showed that $T g R O P 18$ targeted the purinergic receptor P2X1 of the human neural cells and inhibited ATP-induced apoptosis through the mitochondrial pathway.

\section{Methods \\ Reagents}

The apoptosis inducer ATP was purchased from SigmaAldrich (St. Louis, USA), the P2X1 antagonist NF449 from Tocris Bioscience (Minneapolis, USA), Fluo-4 AM from Dojindo Laboratories (Mashiki-machi, Japan), cell mitochondria isolation kit from Beyotime Biotechnology (Beijing, China) and Lipofectamine ${ }^{\circledR} 3000$ transfection 
kit from Thermo Fisher Scientific (Waltham, USA). An isothiocyanate (FITC)-Annexin V/propidium iodide (PI) apoptosis detection kit, TUNEL in situ cell death detection kit and JC-1 mitochondria membrane potential detection kit were purchased from KeyGen (Nanjing, China); protein A-agarose immunoprecipitation reagent and normal rabbit IgG from Santa Cruz Biotechnology (California, USA); HA-tag rabbit mAb, HA-tag mouse $m A b, \beta$-actin rabbit $m A b$, caspase- 3 rabbit $m A b$, caspase-7 rabbit $m A b$, caspase- 9 rabbit $m A b$ and PARP rabbit mAb from Cell Signaling Technology (Boston, USA); Bax rabbit $\mathrm{mAb}, \mathrm{Bcl} 2$ rabbit $\mathrm{mAb}$, Cyt $\mathrm{C}$ rabbit $\mathrm{mAb}$, P2X1 rabbit pAb and cytochrome $\mathrm{C}$ oxidase IV (COXIV) rabbit mAb from Abcam (Cambridge, UK); and DDDDKTag Mouse mAb from Abclonal (Boston, USA).

\section{Cell culture}

The human monocyte/macrophage cell line THP-1 (ATCC, Virginia, USA) and human glioblastoma cell line SF268 (ATCC) were propagated in Roswell Park Memorial Institute 1640 medium (RPMI 1640; Thermo Fisher Scientific) supplemented with $10 \%(\mathrm{v} / \mathrm{v})$ fetal bovine serum (FBS; Thermo Fisher Scientific, Massachusetts, USA), $100 \mathrm{U} / \mathrm{ml}$ penicillin and $100 \mu \mathrm{g} / \mathrm{ml}$ streptomycin (Thermo Fisher Scientific, Massachusetts, USA) at $37{ }^{\circ} \mathrm{C}$ and $5 \% \mathrm{CO}_{2}$. The mouse monocyte/macrophage cell line RAW264.7 (ATCC), the Cercopithecus aethiops kidney fibroblast cell line COS7 (ATCC), and the human foreskin fibroblast cell line HFF (ATCC) were cultured in Dulbecco's modified Eagle medium (DMEM; Thermo Fisher Scientific) supplemented with $10 \%(\mathrm{v} / \mathrm{v})$ FBS, $100 \mathrm{U} / \mathrm{ml}$ penicillin and $100 \mu \mathrm{g} / \mathrm{ml}$ streptomycin at $37^{\circ} \mathrm{C}$ and $5 \% \mathrm{CO}_{2}$.

\section{Toxoplasma gondii culture, cell infection and induction of apoptosis}

Type I strain RH, RH- rop18, RH-ROP18-GFP-Flag, type II strain ME49 and type III strain VEG were cultured in HFFs in DMEM supplemented with $1 \%(\mathrm{v} / \mathrm{v})$ FBS, $100 \mathrm{U} / \mathrm{ml}$ penicillin and $100 \mu \mathrm{g} / \mathrm{ml}$ streptomycin at $37{ }^{\circ} \mathrm{C}$ and $5 \% \mathrm{CO}_{2}$. Three to five days later, when most of the cells were ready to be ruptured by the tachyzoites, the cells were scraped and harvested by passing through a syringe multiple time. The tachyzoites were then purified by passing them through a 3- $\mu \mathrm{m}$ filter (Whatman, Kent, UK), pelleting at $2500 \times \mathrm{rpm}$ for $10 \mathrm{~min}$ and resuspending in DMEM. The tachyzoites were counted with a hemocytometer.

Before infection, THP-1 were cultured in the presence of $100 \mathrm{ng} / \mathrm{ml}$ phorbol 12-myristate 13-acetate (PMA; Abcam) for $24 \mathrm{~h}$ for differentiation into macrophages as described previously [34]. THP-1, RAW264.7 and SF268 cells were infected with RH, ME49 and VEG strains at a multiplicity of infection (MOI) of 3 and incubated for 2 or $22 \mathrm{~h}$ at $37{ }^{\circ} \mathrm{C}$ in $5 \% \mathrm{CO}_{2}$. Before induction of apoptosis, cells were washed with phosphate buffered saline (PBS) to remove non-adherent parasites, and then the THP-1 cells, SF268 cells and RAW264.7 cells were all treated with $1 \mathrm{mg} / \mathrm{ml}$ ATP for 4 or $6 \mathrm{~h}$, and the apoptotic level of the cells was analyzed by the AnnexinV-FITC/PI and TUNEL assay.

$\mathrm{RH}$-wild type and $\mathrm{RH}-\Delta$ rop 18 tachyzoites were separated from the host cells by centrifugation, then the SF268, THP-1 and RAW264.7 cells were infected with the $\mathrm{RH}$-wild type and $\mathrm{RH}-\Delta r o p 18$ tachyzoites at $\mathrm{MOI}=13$. Cells were washed with PBS at $12 \mathrm{~h}$ post-infection and then treated with $1 \mathrm{mg} / \mathrm{ml}$ ATP for an additional $12 \mathrm{~h}$ to induce apoptosis. The apoptotic levels of the cells were analyzed by AnnexinV-FITC/PI assay.

\section{Flow cytometry detection of apoptosis with Annexin V-FITC/PI staining}

The apoptotic levels of RAW264.7, THP-1 and SF268 cells were determined with annexin V- FITC/PI kit. Cells were briefly digested with $0.25 \%$ trypsin (Thermo Fisher Scientific) and washed twice with cold PBS. Then, they were resuspended in $500 \mu \mathrm{l}$ of binding buffer, $5 \mu \mathrm{l}$ of annexin V- FITC and $5 \mu \mathrm{l}$ of PI and incubated at room temperature for $15 \mathrm{~min}$ in the dark. Annexin V-FITC binds to phosphatidylserine on the outer membrane of apoptotic cells, while PI enters and stains cells with compromised membrane integrity and then binds to and labels DNA. A flow cytometer (BD FACSCalibur; BD Biosciences, New Jersey, USA) was used for data collection, and FlowJo software for data analysis. The FSC-H/FSC-A dot plot was used to exclude clumped cells to select single cells. The cells in the annexin V-FITC ${ }^{+} / \mathrm{PI}^{-}$, annexinV-FITC ${ }^{+} /$ $\mathrm{PI}^{+}$and annexin $\mathrm{V}-\mathrm{FITC}^{-} / \mathrm{PI}^{+}$quadrants were counted as apoptotic cells.

\section{TUNEL assay}

In situ labeling of fragmented DNA was performed using the terminal deoxynucleotidyl transferase dUTP nick end labeling (TUNEL) method following the manufacturer's protocol. RAW264.7, THP-1 and SF268 cells were fixed with $4 \%$ formaldehyde and then permeabilized with $0.1 \%$ Triton-X-100 in $10 \mathrm{mM}$ PBS. After washing 3 times with PBS, the cells were incubated in biotin-labeled dUTP solution for $60 \mathrm{~min}$ at $37^{\circ} \mathrm{C}$. After washing 3 times with PBS, the cells were incubated in streptavidin-fluorescein solution for $30 \mathrm{~min}$ at $37^{\circ} \mathrm{C}$. Then, the stained cells and total cells were calculated under a fluorescence microscope (Nikon, Tokyo, Japan), and the mean percentage of the stained cells among the total cells was calculated from 10 representative fields per coverslip. Finally, the mean percentage was calculated from the quadruplets in 
each treatment group. Four repetitive experiments were performed for statistical analysis.

Fluorescence resonance energy transfer (FRET) experiment COS7 cells were cultured in plates the day before transfection. pECFP-N1-ROP18 and pEYFP-C1-P2X1 were co-transfected into COS7 cells for the experimental group. pECFP-N1 and pEYFP-C1 were co-transfected into COS7 cells as a negative control and pEYFP-CFP was transfected into COS7 cells as a positive control [35]. Forty-eight hours post-transfection, the cells were fixed in $4 \%$ paraformaldehyde at $37{ }^{\circ} \mathrm{C}$ for $30 \mathrm{~min}$ and then washed twice with PBS. The FRET efficiency of the different transfection groups was measured under a confocal laser scanning microscope (FLUOVIEW FV1000; Olympus, Tokyo, Japan) [36]. Ten fields were evaluated, and four repetitive experiments performed independently for statistical analysis.

\section{Co-immunoprecipitation analysis}

SF268 and COS7 cells were grown in T75 flasks to 100\% confluence. SF268 cells were infected with or without the RH-ROP18-GFP-Flag strain for $36 \mathrm{~h}$. COS7 cells were transfected with pcDNA3.1-P2X1-HA (or pcDNA3.1-P2X1 $\Delta 339$-399-HA) individually or together with pcDNA3.1-ROP18-3 $\times$ Flag for $48 \mathrm{~h}$. The cells were washed 3 times with PBS and lysed using cell lysis buffer (Beyotime) with $1 \mathrm{mM}$ phenylmethanesulfonyl fluoride (Dingguo Changsheng Biotechnology, Beijing China). Cell lysates were centrifuged at $14,000 \times g$ for $10 \mathrm{~min}$ at $4{ }^{\circ} \mathrm{C}$. The supernatants were harvested and incubated with the primary antibody anti-HA antibody (3724S, CST), anti-FLAG antibody (F1804, Sigma Aldrich) or rabbit normal IgG for $2 \mathrm{~h}$ at $4{ }^{\circ} \mathrm{C}$ with gentle rotation. Then, protein A-agarose (Santa Cruz Biotechnology) was added to the mix and incubated overnight at $4{ }^{\circ} \mathrm{C}$ with gentle rotation. The beads were collected by centrifugation at $500 \times g$ for $5 \mathrm{~min}$ at $4{ }^{\circ} \mathrm{C}$ and then resuspended in SDS-PAGE sample buffer (TransGen, Beijing, China). The samples were boiled, loaded onto the gels for SDSPAGE and then analyzed by Western blotting (WB) [37].

\section{Observation of the effect of TgROP18 overexpression on ATP-induced host cell apoptosis}

COS7 cells were transfected with pcDNA3.1-ROP18$3 \times$ Flag individually or together with pcDNA3.1-P2X1$\mathrm{HA}$. At $48 \mathrm{~h}$ post-transfection, the COS7 cells were treated with $60 \mu \mathrm{g} / \mathrm{ml}$ ATP for $24 \mathrm{~h}$ to induce apoptosis. SF268 cells were treated with $4 \mu \mathrm{M}$ NF449 (P2X1 receptor antagonist) for $2 \mathrm{~h}$ and then subjected to $1 \mathrm{mg} / \mathrm{ml}$ ATP treatment for $12 \mathrm{~h}$. The normal control cells were treated with neither NF449 nor ATP. The apoptosis rate of the cells was analyzed by FCM after annexin V-FITC/ PI staining.

\section{Detection of calcium influx with Fluo-4 AM in COS7 cells}

COS7 cells were grown in 24-well plates and transfected with pcDNA3.1-ROP18-Flag individually or together with pcDNA3.1-P2X1-HA plasmids for $72 \mathrm{~h}$. The cells were then harvested and washed twice with Hank's balanced salt solution (HBSS; Thermo Fisher Scientific). Two hundred and fifty microliters of $5 \mu \mathrm{M}$ Fluo-4 AM (an indicator of intracellular calcium ions; Dojindo Laboratories, Kumamoto, Japan) was added to the cells and incubated for $30 \mathrm{~min}$ at $37^{\circ} \mathrm{C}$. After being washed twice with HBSS, the cells were analyzed by FCM. Fluo-4 AM is virtually non-fluorescent, and acetoxymethyl (AM) ester moiety allows this dye to cross the cell membrane, whereupon endogenous esterases cleave the AM group to liberate the active dye and $\mathrm{Ca}^{2+}$ can bind to Fluo-4 intracellularly to emit green fluorescence. Time series reads were collected every $2 \mathrm{~s}$ for $100 \mathrm{~s}$, and the mean value was calculated as the baseline read F0 (referred to as background). Following $60 \mu \mathrm{g} / \mathrm{ml}$ ATP stimulation, the green fluorescence intensity, reflecting the level of the free intracellular calcium ions in each group, was recorded for $500 \mathrm{~s}$ by FCM. The intracellular calcium level was quantified by the ratio of the strongest fluorescence signal to the basal signal (F/F0).

\section{Detection of mitochondrial membrane depolarization with JC-1 staining}

SF268 cells were infected with $\mathrm{RH}$ or $\mathrm{RH}-\Delta$ rop 18 tachyzoites (MOI = 13). Twelve hours later, $1 \mathrm{mg} / \mathrm{ml}$ ATP was added to the cells to induce apoptosis for $12 \mathrm{~h}$. The cells were then digested with $0.25 \%$ trypsin and rinsed twice with PBS. Five hundred microliters of incubation buffer containing $1 \mu \mathrm{l}$ of JC-1 was added to the cells and incubated for $15 \mathrm{~min}$ at $37{ }^{\circ} \mathrm{C}$ in $5 \% \mathrm{CO}_{2}$. The cells were then visualized under a fluorescence microscope (Nikon) and subjected to FCM (BD Biosciences). Twenty views were obtained under GFP and RFP fluorescence filters, and the fluorescence intensities were determined using ImageJ software. This experiment was repeated four times for statistical analysis. For FCM, JC-1 was excited with a 488 $\mathrm{nm}$ argon laser, and JC-1 green and red fluorescence were recorded in the FL1 and FL2 channels. A minimum of 10,000 cells within the gated region were analyzed. The value was calculated by the relative intensities of green to red fluorescence. Staining with the lipophilic, cationic dye JC-1 can discriminate polarized and depolarized mitochondria, because in polarized mitochondria, the normal green fluorescent JC-1 dye forms red fluorescent aggregates in response to their higher membrane potential, while in depolarized mitochondria, the red fluorescent aggregates 
are converted to the monomeric form and exhibit green fluorescence [38].

\section{Separation of cytosolic and mitochondrial proteins in SF268 cells}

Mitochondrial and cytosolic proteins were separated using a cell mitochondria isolation kit. SF268 cells were harvested and washed twice with cold PBS, and then incubated in $100 \mu \mathrm{l}$ of ice-cold mitochondrial lysis buffer with gentle rotation at $4{ }^{\circ} \mathrm{C}$ for $15 \mathrm{~min}$. The cell suspension was then transferred into a glass homogenizer and homogenized on ice for 30 strokes using a tight pestle. The homogenate was subjected to centrifugation at $600 \times g$ for $10 \mathrm{~min}$ at $4{ }^{\circ} \mathrm{C}$ to remove nuclei and unbroken cells. Then, the supernatant was collected and centrifuged again at $12,000 \times g$ for $10 \mathrm{~min}$ at $4{ }^{\circ} \mathrm{C}$ to obtain the cytosolic (supernatant) and mitochondrial (pellet) fractions. Cyt $\mathrm{C}, \mathrm{Bcl} 2$ and Bax proteins in the cytosol and mitochondria were detected by western blotting. The intensity of Cyt $\mathrm{C}, \mathrm{Bcl} 2$ and Bax bands with unsaturated exposure from four independent experiments were analyzed using ImageJ software, and the proportions of Cyt C, Bcl2 and Bax to the loading control Actin or COXIV were calculated.

\section{Western blotting}

Protein samples were diluted in $6 \times$ SDS PAGE loading buffer and then boiled for $10 \mathrm{~min}$. The boiled samples were loaded onto 15\% SDS-polyacrylamide gels for electrophoresis and then transferred to a polyvinylidene fluoride (PVDF) membrane. After transfer, the PVDF membrane was blocked in PBS/ $5 \%$ bovine serum albumin (BSA) $/ 0.05 \%$ Tween- 20 at $37{ }^{\circ} \mathrm{C}$ for $2 \mathrm{~h}$ with gentle shaking, followed by probing with the primary antibody at $4{ }^{\circ} \mathrm{C}$ overnight. Then, the membrane was incubated with the secondary antibody at $37^{\circ} \mathrm{C}$ for $2 \mathrm{~h}$. The PVDF membranes were visualized by enhanced chemiluminescence (ECL) detection and photographed as recommended by the manufacturer.

\section{Statistical analysis}

All experiments were repeated four times. The data were analyzed using GraphPad Prism 5 (San Diego, CA, USA). Statistical significance was determined using the KruskalWallis $\mathrm{H}$-test with Bonferroni correction, and ${ }^{*} P<0.05$ and ${ }^{* *} P<0.01$ were considered to indicate a significant difference. The statistical comparisons presented in the figures are provided in Additional file 1: Table S1.

\section{Results}

Infection by three types of $T$. gondii strains (RH, ME49 and VEG) inhibited ATP-induced apoptosis of SF268, THP-1 and RAW264.7 cells

Human SF268 neural cells were infected with T. gondii RH (type I), ME49 (type II) and VEG (type III), individually, for 2 or $22 \mathrm{~h}$, and then were treated with ATP for 4 or $6 \mathrm{~h}$ to induce apoptosis. Our FCM results obtained with annexin V-FITC/PI staining indicated that there were significantly fewer apoptotic SF268 cells in any of the infected groups than that in the uninfected control, at both 6 and 28 h post-infection (Fig. 1a, b1, b2). Moreover, the TUNEL assay results also showed that T. gondii infection inhibited DNA fragmentation (Additional file 2: Figure S1). The same experiments were performed on the other two cell types, human THP-1 and mouse RAW264.7 monocyte/macrophage cells. The FCM results were similar to those observed with human SF268 glial cells (Fig. 2a, b1, b2 for RAW264.7 cells; Fig. 3a, b1, b2 for THP- 1 cells). The TUNEL assay results obtained with these two types of cells also showed that the DNA fragmentation was less evident in any of the infected groups compared with their uninfected group (Additional file 3: Figure S2 for RAW264.7 cells; Additional file 4: Figure S3 for THP-1 cells). These results suggest that ATP-induced cell apoptosis was significantly inhibited by $T$. gondii infection, regardless of the tested strain types and host cell types.

\section{TgROP18 was a regulator for inhibition of ATP-induced apoptosis of SF268 cells}

Based on previous reports, $\operatorname{TgROP} 18$ of RH strain modulates host cell apoptosis, but the results are dependent on the type of cells infected by $T$. gondii $[14,15]$. To evaluate whether apoptosis of SF268, THP-1 and RAW264.7 cells was influenced by $\operatorname{TgROP} 18$, the three cell types were infected with $\mathrm{RH}-\Delta$ rop 18 or $\mathrm{RH}$ wild type tachyzoites at an MOI of 13 for $12 \mathrm{~h}$, followed by ATP treatment for $12 \mathrm{~h}$ to induce apoptosis. Normal and ATP-treated cells were used as negative and positive controls, respectively. The FCM results showed that the apoptotic rate of the SF268 cells infected with RH strain was significantly lower than that of RH- $\Delta$ rop18-infected SF268 group $(\mathrm{C} 2=-7, d f=3, P=0.037)$ (Fig. 4a, b). However, this phenomenon was not observed in THP-1 and RAW264.7 cells, as both the $\mathrm{RH}$ and $\mathrm{RH}-\Delta$ rop 18 -infected groups showed a lower percentage of apoptotic cells compared with the ATP treated group, and no significant difference was observed between the RH and RH- rop 18-infected groups (Additional file 5: Figure S4a, b). These results indicated that TgROP18 inhibited apoptosis of SF268 cells, but it played no observable role in modulating the apoptosis of THP-1 and RAW264.7 cells.

\section{TgROP18 targeted the host cell carboxyl-terminal region of $\mathrm{P} 2 \mathrm{X} 1$}

To understand the molecular mechanism by which TgROP18 inhibits cell apoptosis and identify its targets in host cells, we performed a genome-wide screening of 


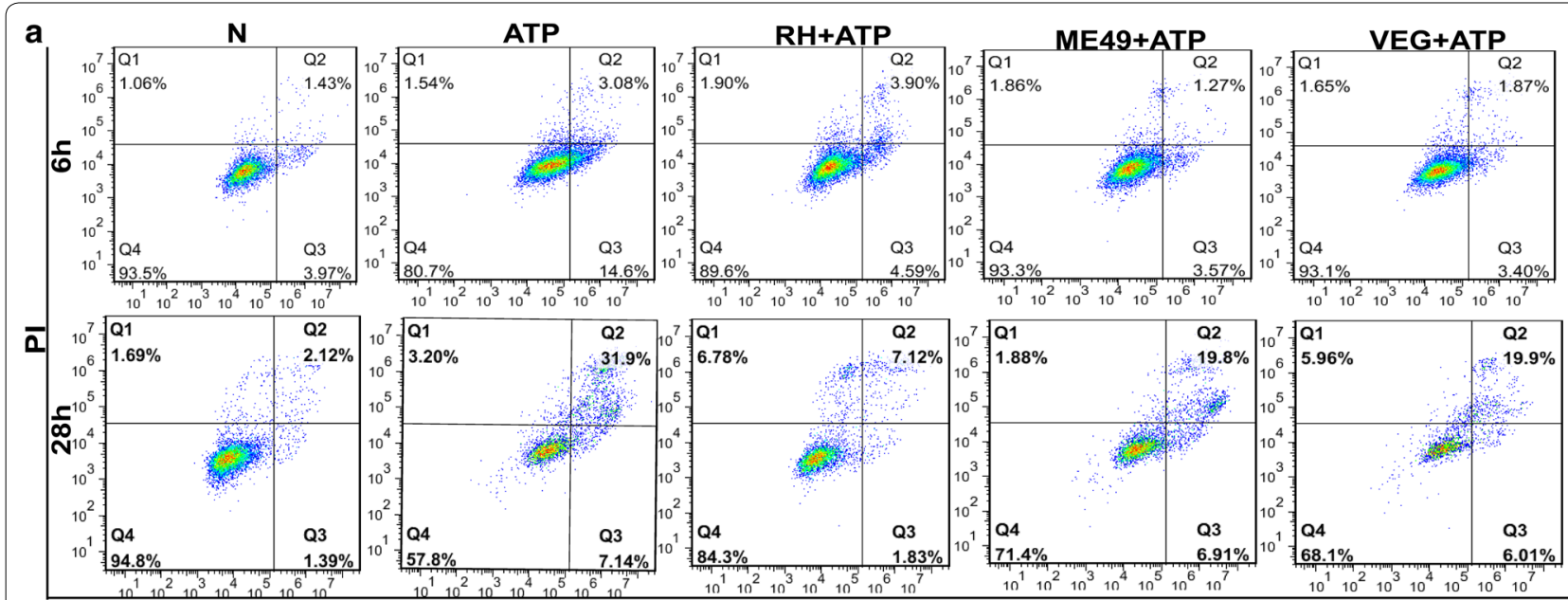

Annexin V-FITC

b1

SF268-6h

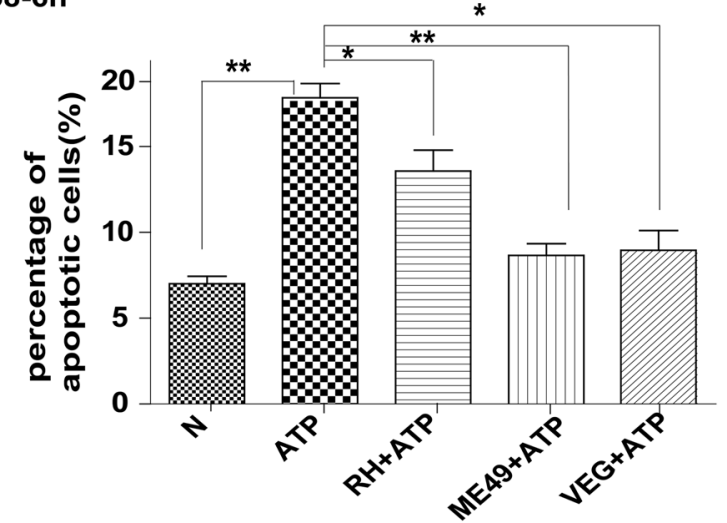

b2

SF268-28h

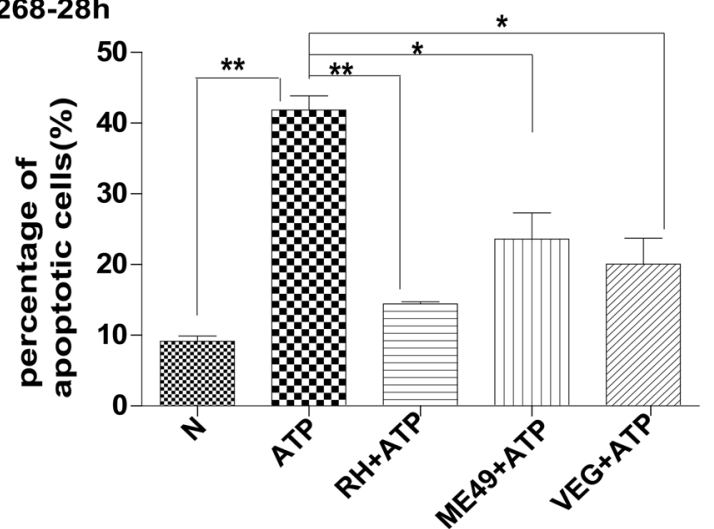

Fig. 1 Effects of T. gondii infection on ATP-induced apoptosis of human SF268 neural cells. SF268 cells were infected with the RH, ME49 or VEG strain of T. gondii $(\mathrm{MOI}=3)$ for 2 or $22 \mathrm{~h}$, followed by ATP induction for 4 or $6 \mathrm{~h}$. The cells were harvested at 6 or $28 \mathrm{~h}$ post-infection for apoptosis measurement by flow cytometry after annexin V-FITC/PI staining. Representative flow cytometry data are presented in panel a and quantified in panels $\mathbf{b} \mathbf{1}$ and $\mathbf{b} 2$. The experiments were repeated four times. The values were analyzed using the Kruskal-Wallis $\mathrm{H}$-test and Bonferroni correction $\left({ }^{*} P<0.05,{ }^{* *} P<0.01\right)$

human targets for $T g R O P 18$ of the RH strain with the bimolecular fluorescence complementation (BiFC) technique. The technique is based on two non-fluorescent fragments (YFP $\mathrm{N}$-terminus and C-terminus) of the yellow fluorescent protein (YFP) that can reconstitute the fluorophore only when the two fragments are brought together by interactions between proteins that are covalently linked to each fragment [39]. P2X1 was identified as a putative interacting partner of $T g R O P 18$ [40]. To verify this interaction, we performed a FRET assay. For the FRET experiment, pECFP-ROP18 was a donor, and pEYFP-P2X1 an acceptor. If the interaction exists, the energy of the donor will transfer to the acceptor and they will reconstitute the functional fluorescent entity. As shown in Fig. 5a, the different color bands represent different ranges of FRET efficiencies: the dark blue represents the FRET efficiency of $<25 \%$, the green for the FRET efficiency range of $25-50 \%$, and the red for the FRET efficiency range of $>50 \%$. The FRET efficiency of pECFP-ROP18 and PEYFP-P2X1 was significantly higher than pECFPn1-pEYFPc1 FRET efficiency. This further confirmed the interaction of TgROP18 with P2X1 in the cytosol of COS7 cells (Fig. 5a, b). The COS-7 cell line shows high efficiency of plasmid transfection and exogenous gene overexpression, and thus, it is very suitable for the overexpression of proteins for co-IP and FRET. SF268 is a human neural cell with P2X1 expression, which is suitable for co-IP of endogenous P2X1 and ROP18 after T. gondii infection. To further assess the specificity of this interaction, we overexpressed Flag-tagged TgROP18 


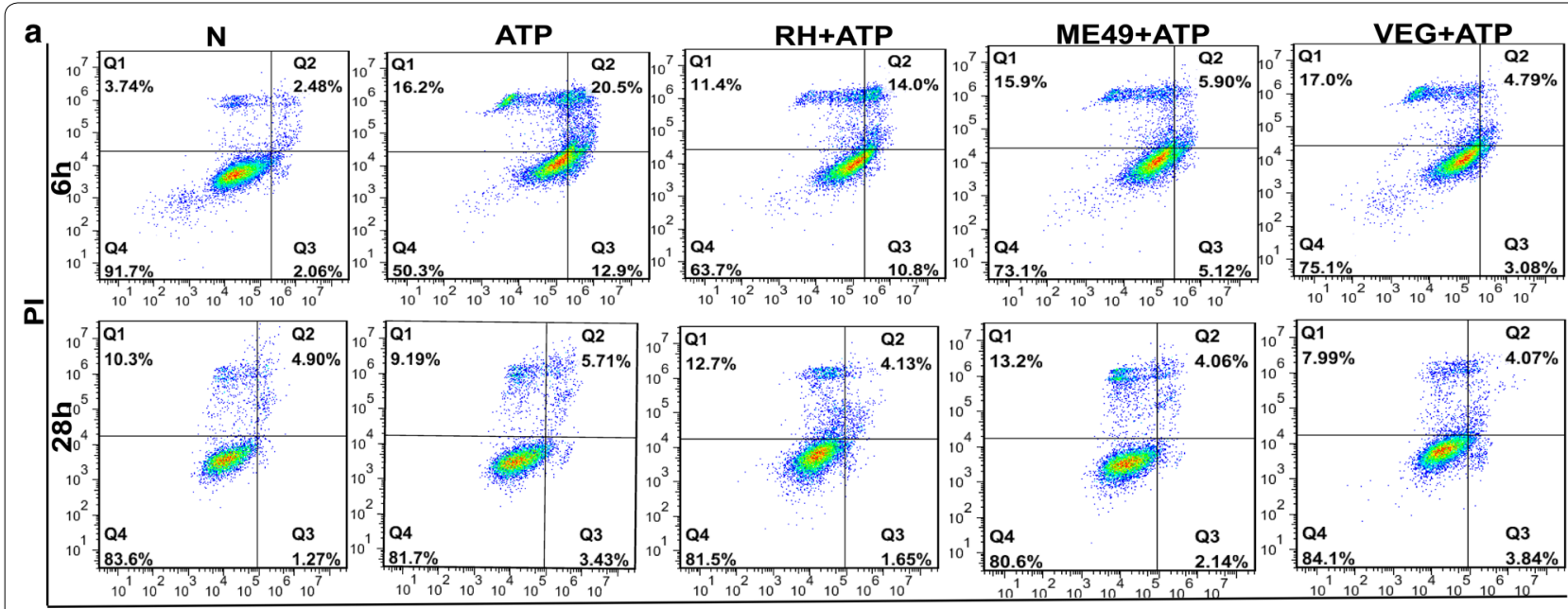

\section{Annexin V-FITC}

b1

RAW264.7-6h

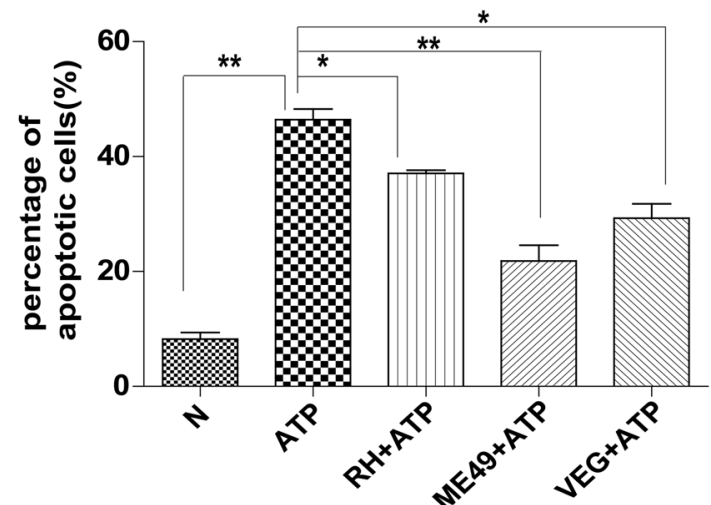

b2

RAW264.7-28h

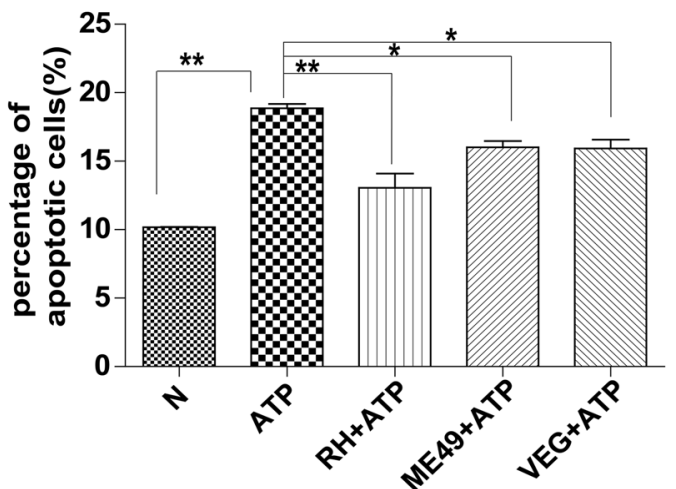

Fig. 2 Effects of T. gondii infection on ATP-induced apoptosis of mouse RAW264.7 macrophage cells. RAW264.7 cells were infected with the RH, ME49 or VEG strain of T. gondii and followed by ATP induction 4 or $6 \mathrm{~h}$. The cells were harvested at 6 or $28 \mathrm{~h}$ post-infection for apoptosis measurement by flow cytometry after annexin V-FITC/PI staining. Representative flow cytometry data are presented in panel a and quantified in panels $\mathbf{b} 1$ and $\mathbf{b} 2$. The experiments were repeated four times. The values were analyzed using the Kruskal-Wallis $\mathrm{H}$-test and Bonferroni correction $\left({ }^{*} P<0.05,{ }^{* *} P<0.01\right)$

together with HA-tagged P2X1 in COS7 cells, and the cell lysates were subjected to the immunoprecipitation assay using an anti-HA antibody. The results indicated that the overexpressed Flag-tagged $\operatorname{TgROP} 18$ was immunoprecipitated by the overexpressed HA-tagged P2X1 (Fig. 5c). The cell lysate of SF268 cells infected with RHROP18-GFP-Flag strain was immunoprecipitated with anti-Flag antibody, and the immunoblotting results indicated that the endogenous P2X1 from SF268 cells could be immunoprecipitated by TgROP18 tagged with Flag from the RH-ROP18-GFP-Flag strain (Fig. 5d).

Previous studies have shown that the $\mathrm{C}$-terminus of the P2X1 receptor plays an important role in the regulation of its expression and gating activity [41]. To understand whether this domain was involved in binding to $T g \mathrm{ROP} 18$, we constructed a pcDNA3.1-P2X1 $\Delta 339$ 399-HA plasmid with a deletion of the P2X1 C-terminus (amino acids 339-399) and co-transfected with pcDNA3.1-ROP18-3 $\times$ Flag into COS7 cells. The results showed that Flag-tagged TgROP18 could not be immunoprecipitated by P2X1 carrying the C-terminal deletion when compared with the full-length P2X1, which was used as a positive control (Fig. 5e).

\section{TgROP18 decreased P2X1-mediated apoptosis}

When SF268 cells were pretreated with $4 \mu \mathrm{M}$ NF449 (a specific inhibitor of P2X1 activity [32]) for $2 \mathrm{~h}$ before ATP treatment, the apoptosis rate was significantly 

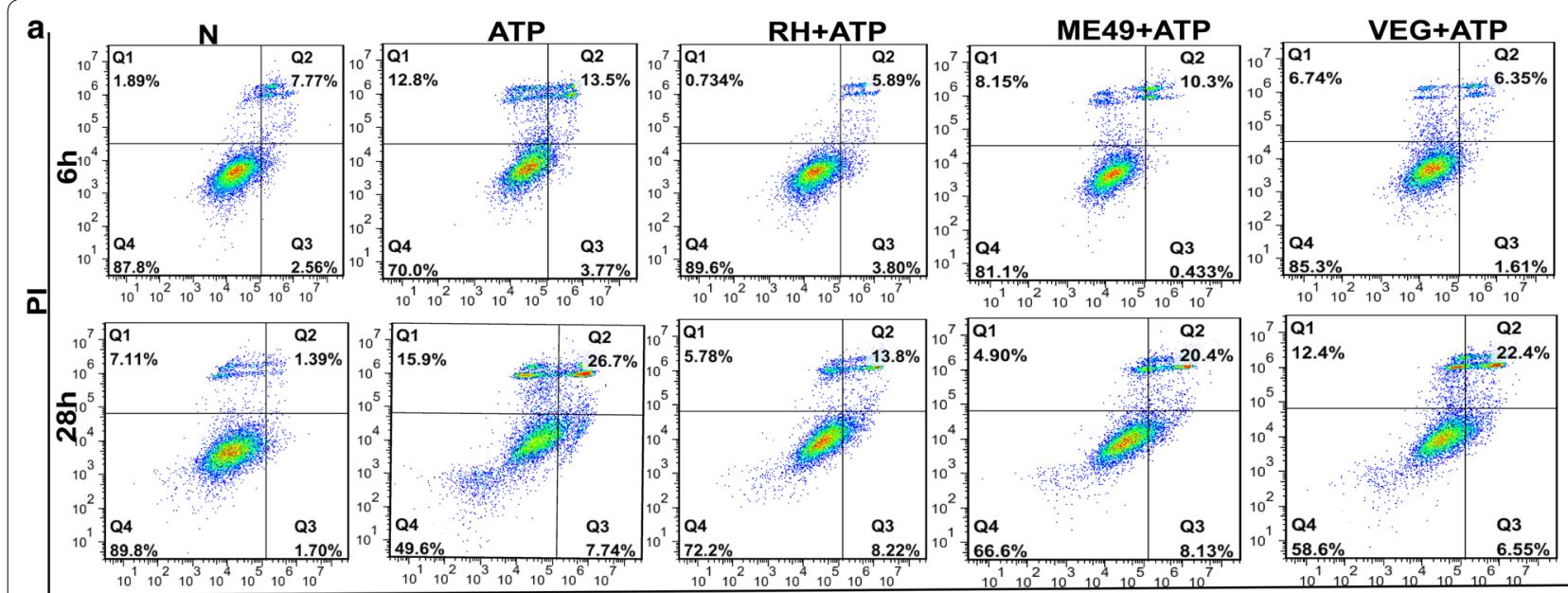

Annexin V-FITC

b1

\section{THP-1-6h}

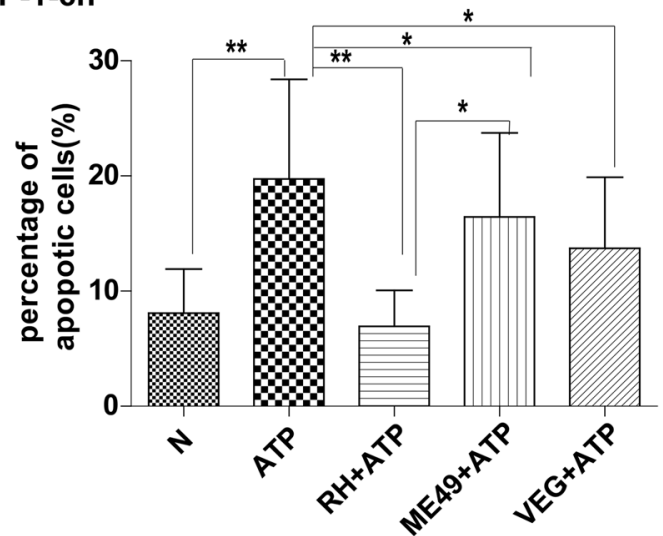

b2

THP-1-28h

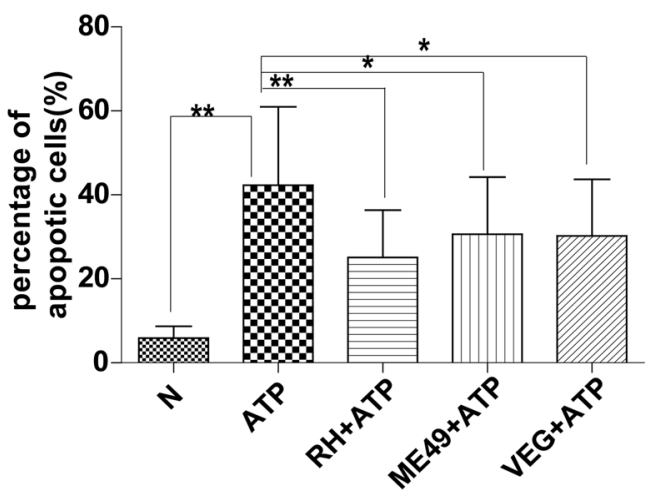

Fig. 3 Effects of T. gondii infection on ATP-induced apoptosis of human THP-1 immune cells. THP-1 cells were infected with the RH, ME49 or VEG strain of T. gondii and followed by ATP induction 4 or $6 \mathrm{~h}$. The cells were harvested at 6 or $28 \mathrm{~h}$ post-infection for apoptosis measurement by flow cytometry after annexin V-FITC/PI staining. Representative flow cytometry data are presented in panel a and quantified in panels $\mathbf{b} \mathbf{1}$ and $\mathbf{b} \mathbf{2}$. The experiments were repeated four times. The values were analyzed using the Kruskal-Wallis $\mathrm{H}$-test and Bonferroni correction $\left({ }^{*} P<0.05\right.$, ${ }^{* *} P<0.01$ )

lower in the NF449 + ATP-treated group than the ATPtreated group $(\mathrm{C} 2=7.735, d f=3, P=0.025)$, indicating that P2X1 was indeed involved in ATP-induced apoptosis (Fig. 6a, c). In contrast, we found that the apoptosis index in the NF449 + ATP treated group was significantly higher than in the NF449-treated group $(\mathrm{C} 2=6.875, d f=3, P=0.04)$, although both of their apoptosis indexes were significantly lower than the ATPtreated group (Fig. 6a, c). These results suggested that P2X1 inhibitor NF449 could not completely inhibit the apoptosis induced by ATP, and some proapoptotic proteins other than P2X1 likely regulated SF268 apoptosis induced by ATP.

To further identify whether TgROP18 inhibited host cell apoptosis through binding to the proapoptotic protein P2X1 of the host cell, untransfected COS7 cells and COS7 cells transfected with pcDNA3.1-TgROP18 and pcDNA3.1-P2X1, individually or together for $48 \mathrm{~h}$, were stimulated with ATP for an additional $24 \mathrm{~h}$. Normal cells (N, untransfected and untreated with ATP) served as the control. The expression of these two proteins was verified by western blotting (Fig. 6b). Cell apoptosis was assessed by FCM following annexin V-FITC/PI staining. The results showed that COS7 cells overexpressing P2X1 had a significantly higher apoptosis index compared with untransfected cells and cells with overexpression of $\operatorname{TgROP} 18$, whereas co-expression of $\operatorname{TgROP} 18$ with P2X1 in COS7 cells significantly decreased ATP-induced apoptosis compared with cells expressing only P2X1 $(\mathrm{C} 2=8.375, d f=4, P=0.045)$ (Fig. 6d). 


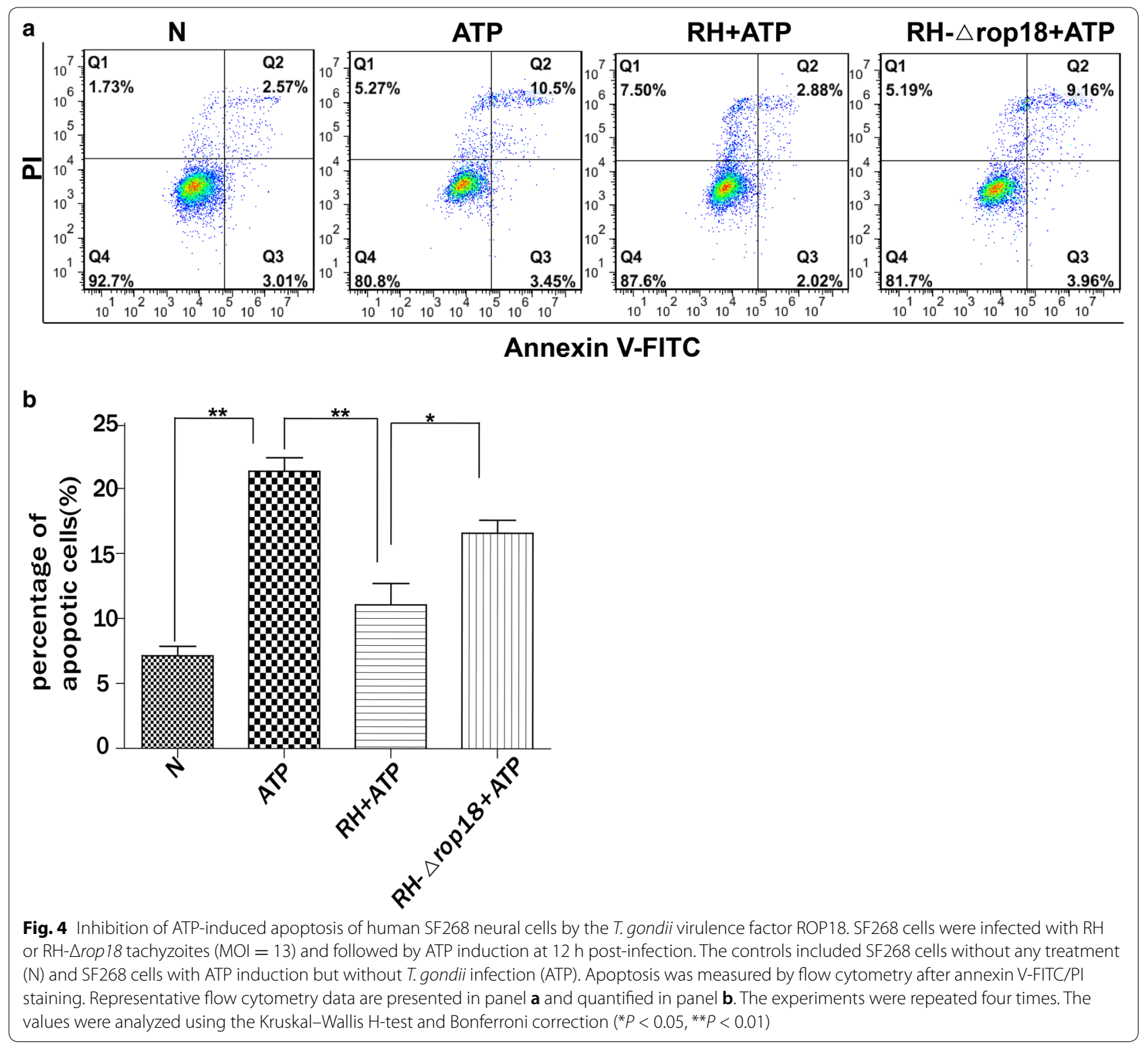

TgROP18 decreased host cell apoptosis through inhibition of P2X1-mediated $\mathrm{Ca}^{2+}$ influx, but not through $\mathrm{P} 2 \mathrm{X} 1$ degradation

TgROP18 and P2X1 were overexpressed in COS7 cells for $72 \mathrm{~h}$, and the intracellular $\mathrm{Ca}^{2+}$ concentration was measured for $600 \mathrm{~s}$ following the addition of $60 \mu \mathrm{g} / \mathrm{ml}$ ATP into the culture medium. We found that P2X1 increased $\mathrm{Ca}^{2+}$ influx after ATP stimulation, and this process could be inhibited by co-expression of TgROP18 in the COS7 cells $(\mathrm{C} 2=7, d f=3, P=0.036)$ (Fig. 7a, b). However, the P2X1mediated $\mathrm{Ca}^{2+}$ increase was not completely inhibited by TgROP18, this indicated that besides P2X1, some other proapoptotic proteins are also involved in regulation of COS7 cells apoptosis. Considering that $T g R O P 18$ can phosphorylate host cell proteins ATF6 $\beta$ and P65 for degradation to suppress the host innate immune response [12,13], we next examined whether ROP18 caused P2X1 degradation. COS7 cells were co-transfected with pcDNA3.1-ROP18Flag and/or pcDNA3.1-P2X1-HA expression vectors for 48 h. The western blot results showed that ROP18 expression did not affect the protein level of P2X1 (Fig. 7c). All these findings revealed that ROP18 inhibited P2X1-mediated $\mathrm{Ca}^{2+}$ influx without causing P2X1 degradation, despite their interaction. 

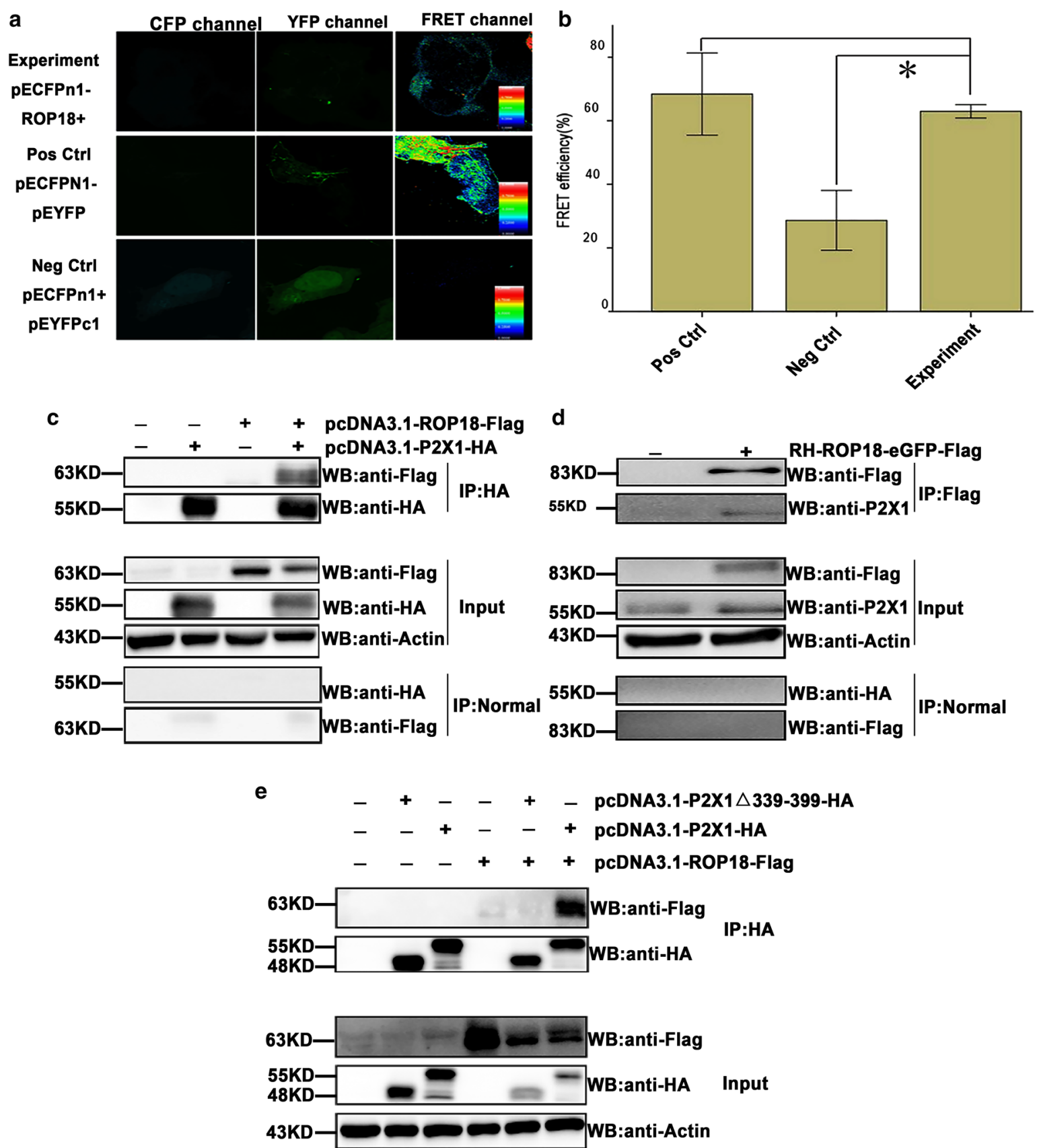

Fig. 5 Identification of host P2X1 purinergic receptor as a TgROP18 target protein by FRET and co-IP. a Representative confocal FRET images. COS7 cells were cultured in plates the day before transfection. The experimental group was co-transfected with pECFP-N1-ROP18 and pEYFP-C1-P2X1, the negative control with pECFP-N1 and pEYFP-C1, and the positive control was transfected with pEYFP-CFP. The cells were fixed for confocal FRET measurement at $48 \mathrm{~h}$ post-infection. The vertical color bars represent FRET intensity, with red for a high FRET signal and blue for a low signal. $\mathbf{b}$ Quantitative analysis of FRET efficiency. c Co-IP analysis of COS7 cells transfected with pcDNA3.1-ROP18-3 xFlag and/or pcDNA3.1-P2X1-HA. Lysates of the COS7 cells transiently transfected with the indicated plasmids or the control cells were immunoprecipitated with the anti-HA antibody and detected by western blotting with the indicated antibodies. $\mathbf{d}$ Co-IP analysis of SF268 cells infected with RH-ROP18-GFP-Flag. Lysates of the infected SF268 cells or the control cells were immunoprecipitated with anti-Flag antibody and detected by western blotting with the indicated antibodies. e Co-IP analysis of COS7 cells transfected with pcDNA3.1-ROP18-3 XFlag and/or pcDNA3.1-P2X1-HA, pcDNA3.1-P2X1 $3339-399-H A$. Lysates of the transfected COS7 cells or the control cells were immunoprecipitated with the anti-HA antibody and detected by western blotting with the indicated antibodies. The FRET efficiency was evaluated from 4 areas. The values were analyzed using the Kruskal-Wallis $\mathrm{H}$-test and Bonferroni correction $\left({ }^{*} P<0.05\right.$, ${ }^{* *} P<0.01$ ) 

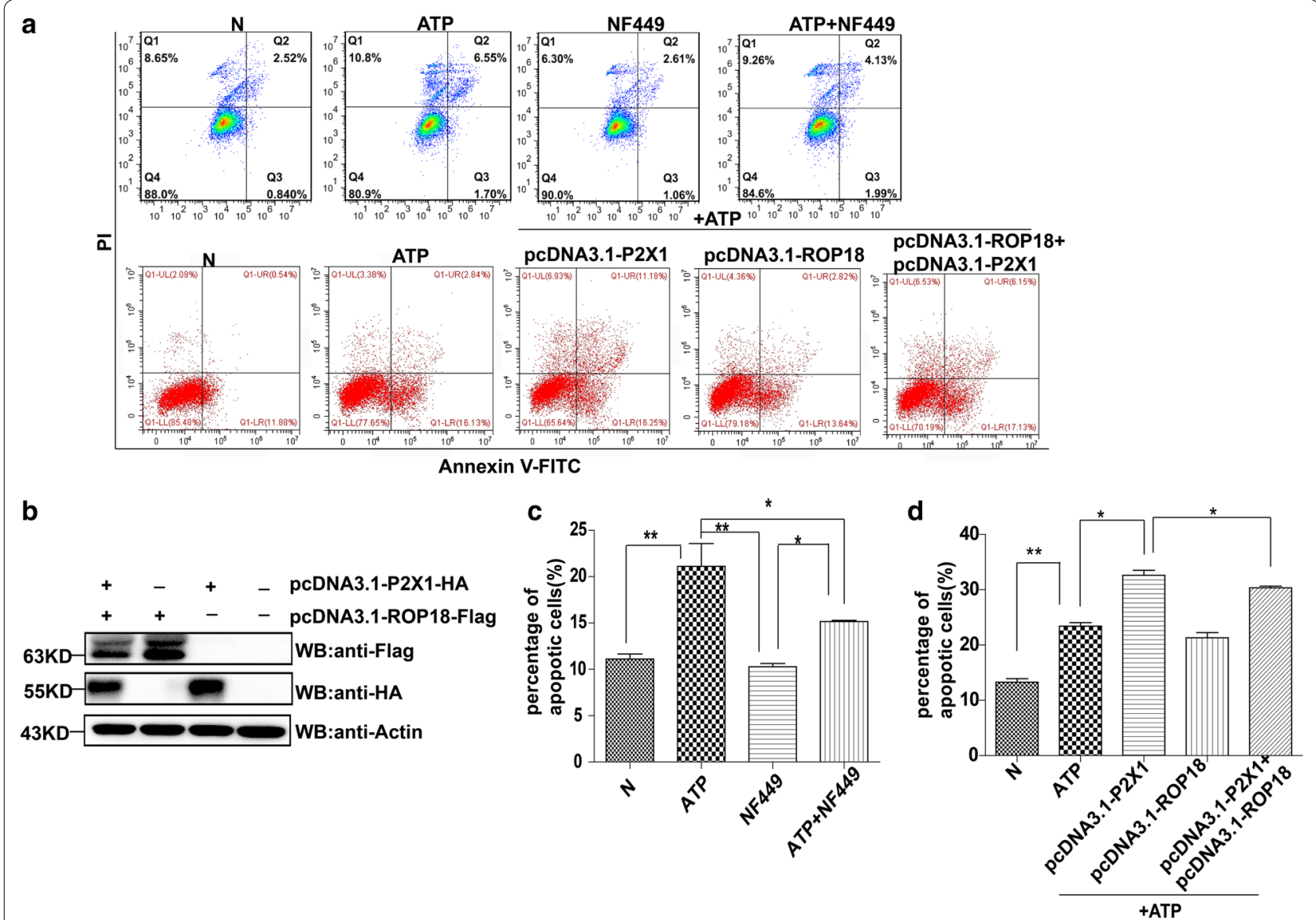

Fig. 6 TgROP18 inhibition of host cell apoptosis promoted by P2X1. Four groups of SF268 cells were treated or not with ATP and/or NF449 as indicated. Five groups of COS7 cells were prepared. The N group is the normal COS7 cells. The other four groups were transfected with pcDNA3.1-ROP18 and/or pCDNA3.1-P2X1 and followed by treatment of ATP and/or NF449 as indicated. a Representative flow cytometry data. The apoptosis rate was measured after annexin V-FITC/PI staining. b Western blotting analysis of the expression of Flag-tagged ROP18 and HA-tagged P2X1 in COS7 cells. c, $\mathbf{d}$ Quantification of the flow cytometry data. The flow cytometry experiments were repeated four times. The values were analyzed using the Kruskal-Wallis H-test and Bonferroni correction $\left.{ }^{*} P<0.05,{ }^{* *} P<0.01\right)$

\section{TgROP18 inhibited mitochondrial depolarization and Cyt C translocation from mitochondria to the cytosol in SF268 cells}

Previous studies have shown that $\mathrm{RH}$ regulates apoptosis of host cells mainly through the mitochondrial pathway [42]. To identify whether this pathway was modulated by $T g$ ROP18 during $T$. gondii infection, we first measured the mitochondrial membrane potential after SF268 cells were infected by $\mathrm{RH}$ or $\mathrm{RH}-\Delta$ rop 18 strain for 12 $\mathrm{h}$ followed by ATP treatment for $12 \mathrm{~h}$. When the mitochondrial membrane is normal, the cationic dye JC-1 forms red fluorescent aggregates accumulated in mitochondria in response to their higher membrane potential, while in a broken mitochondrial membrane, the red fluorescent aggregates are converted to the monomeric form and exhibit green fluorescence accumulated in the cytosol. The intensity ratio of green to red fluorescence reflects the extent of mitochondrial membrane depolarization. Both fluorescence microscopy observation (Fig. 8a, b) and FCM analysis (Fig. 8c, d) showed that the intensity ratio of green to red fluorescence decreased in the $\mathrm{RH}+\mathrm{ATP}$-treated group compared with the ATPtreated group $(\mathrm{C} 2=26, d f=3, P=0.000 ; \mathrm{C} 2=8.25$, $d f=3, P=0.014)$, indicating that infection of the $\mathrm{RH}$ strain inhibited mitochondrial membrane depolarization induced by ATP. Moreover, the intensity ratio of green to red fluorescence also decreased in the $\mathrm{RH}+\mathrm{ATP}$ treatment group compared with the RH- $\Delta$ rop $18+$ ATP treatment group $(\mathrm{C} 2=-22.95, d f=3, P=0.000$; $\mathrm{C} 2=-6.75, d f=3, P=0.045)$, implying that depolarization of the mitochondrial membrane was inhibited by TgROP18. Therefore, an increase in green/red fluorescence ratio means depolarization of the mitochondrial membrane and this phenomenon can be changed by the expression of $T g$ ROP18. 


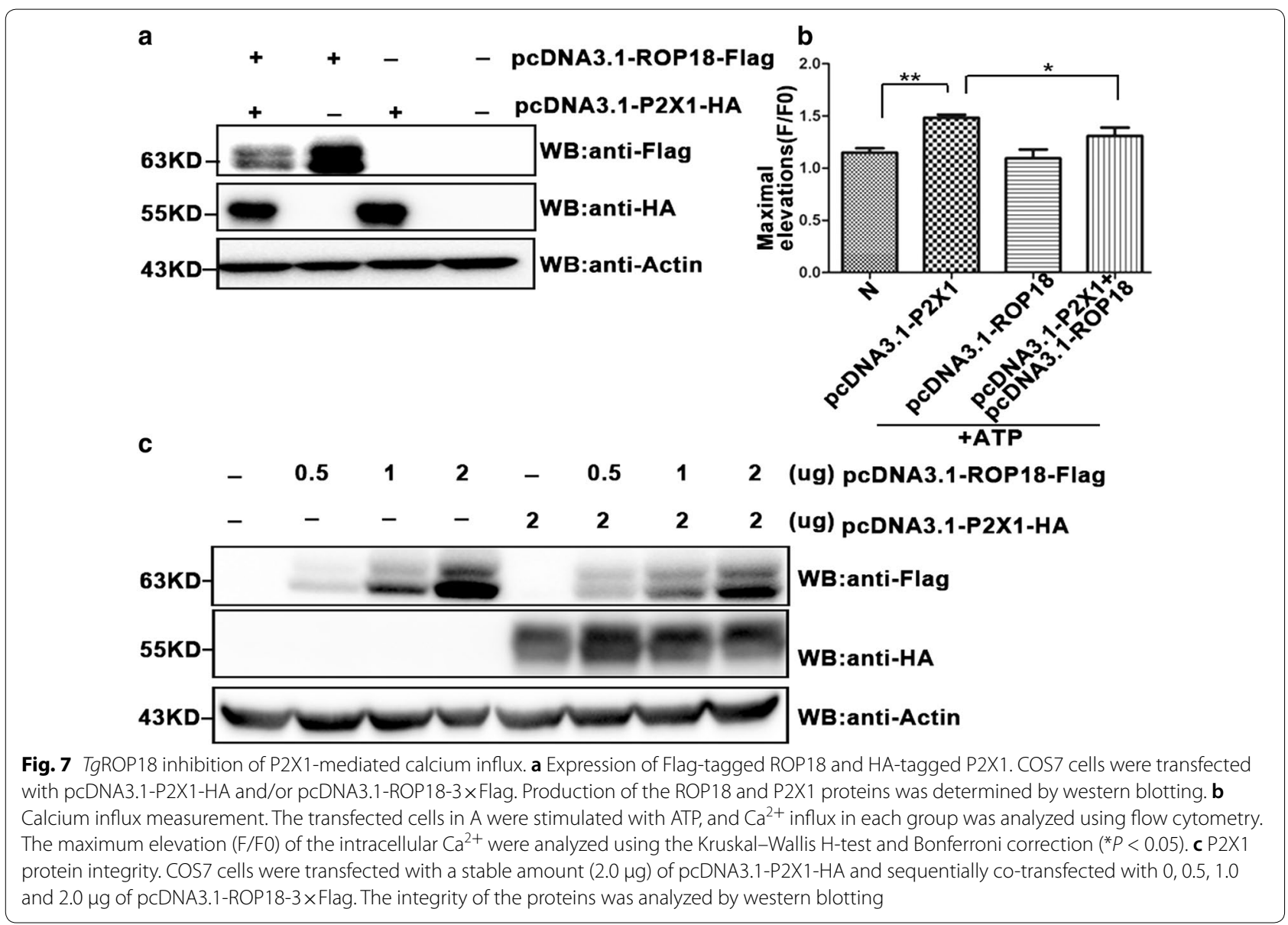

The mitochondrial protein Cyt $\mathrm{C}$ plays an important role in initiating the intrinsic apoptotic pathway. The anti-and the pro-apoptotic family of proteins is tightly associated with the integrity of the mitochondrial outer membrane and release of Cyt $\mathrm{C}$ from mitochondria to the cytosol. To evaluate the apoptotic consequences mediated by $T g R O P 18$, we next measured the release of Cyt $\mathrm{C}$ from mitochondria to the cytosol and the translocation of Bax (a pro-apoptotic Bcl2 family protein) and $\mathrm{Bcl} 2$ (an anti-apoptotic Bcl2 family protein) from the cytosol to mitochondria in each group. The western blot results revealed a relatively higher level of Cyt $C$ in the mitochondrial fraction, but a lower level of Cyt $\mathrm{C}$ was detected in the cytosolic fraction in the RH + ATP treatment group compared with the RH- $\Delta$ rop $18+$ ATP treatment group $(\mathrm{C} 2=-6.75, d f=3, P=0.044 ; \mathrm{C} 2=12$, $d f=3, P=0.000$ ) (Fig. 9a, c1, c2). These findings indicated that $T g R O P 18$ inhibited cyt $\mathrm{C}$ translocation from the mitochondria to the cytosol, and promoted the translocation of anti-apoptotic protein $\mathrm{Bcl} 2$, proapoptotic protein Bax from the cytosol to mitochondria.
Moreover, an increased level of anti-apoptotic protein $\mathrm{Bcl} 2(\mathrm{C} 2=9.5, d f=3, P=0.005)$ and decreased level of proapoptotic protein $\mathrm{Bax}(\mathrm{C} 2=-11.75, d f=3$, $P=0.000)$ relative to COXIV was found in the mitochondrial fraction of the $\mathrm{RH}+$ ATP treatment group compared with the ATP-treated group (Fig. 9b, c3, c4), indicating that $\mathrm{RH}$ infection promoted the translocation of $\mathrm{Bcl} 2$ and inhibited the translocation of $\mathrm{Bax}$ from the cytosol to mitochondria in SF268 cells. Conversely, the protein level of mitochondrial $\mathrm{Bcl} 2$ relative to COXIV was markedly higher in the $\mathrm{RH}+\mathrm{ATP}$ than the $\mathrm{RH}-\Delta$ rop $18+$ ATP treatment group $(\mathrm{C} 2=9.375$, $d f=3, P=0.005)$ (Fig. 9b, c3). As a pro-apoptotic protein, translocation of Bax is supposedly inhibited by $\operatorname{TgROP} 18$; however, we found that $T g R O P 18$ significantly increased the relative Bax level in the mitochondrial fraction by comparing the $\mathrm{RH}+\mathrm{ATP}$ and $\mathrm{RH}-\Delta$ rop $18+\mathrm{ATP}$ treatment groups $(\mathrm{C} 2=7.75, d f=3, P=0.021)$ (Fig. 9b, c4). These results indicated that $T g R O P 18$ increased the relative level of the anti-apoptotic protein $\mathrm{Bcl} 2$ as well as the proapoptotic protein Bax in the mitochondrial 

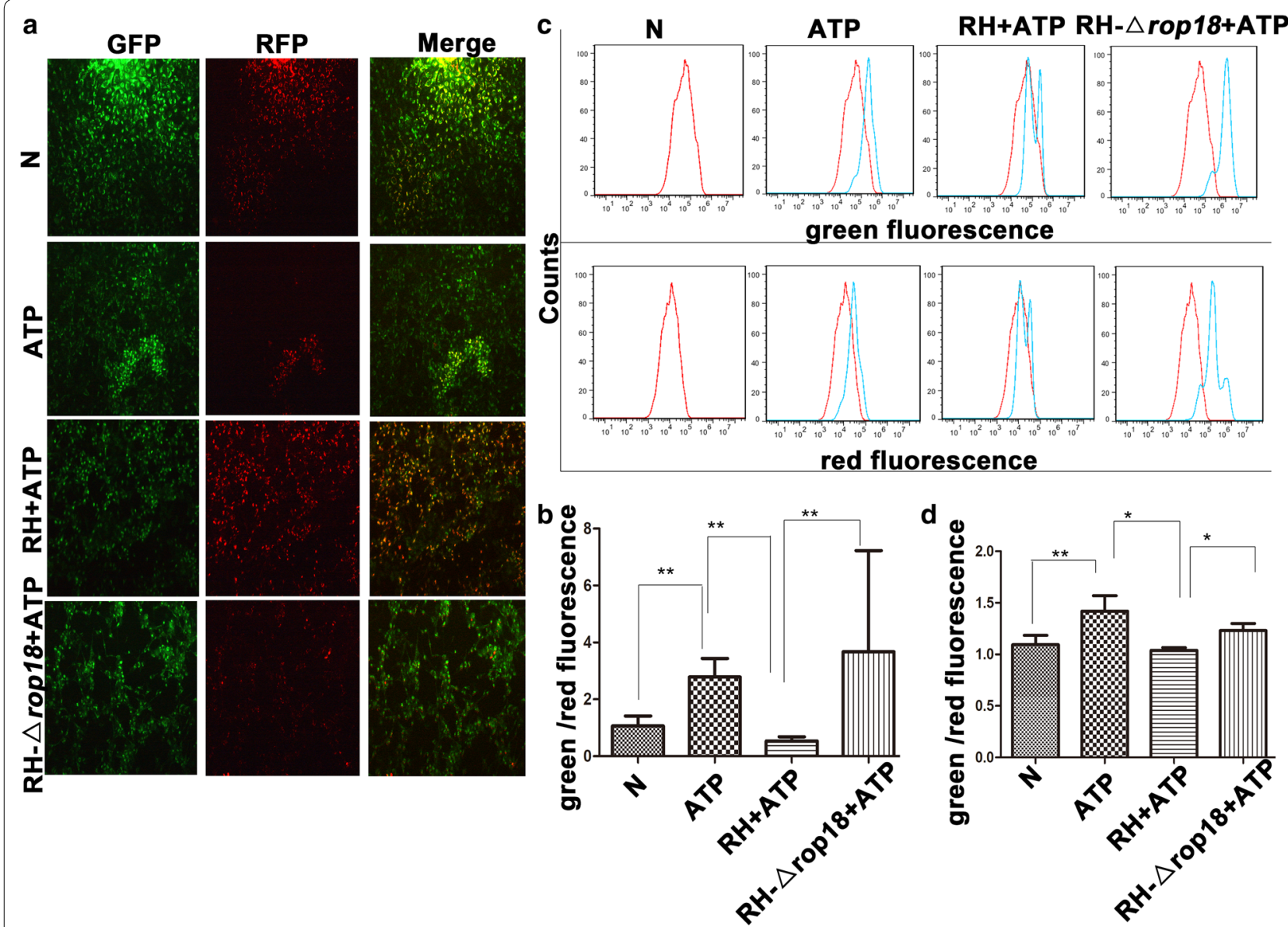

Fig. 8 TgROP18 inhibition of ATP-induced mitochondrial depolarization in SF268 cells. SF268 cells were infected with RH or RH- $\triangle$ rop 18 tachyzoites at $\mathrm{MOI}$ of 13 and followed by ATP induction of apoptosis. a Visualization of mitochondrial membrane depolarization by JC-1 staining and fluorescence microscopy $(10 \times)$. c Flow cytometric analysis of mitochondrial membrane depolarization. b, d Quantification of mitochondrial membrane depolarization. The percentages of green to red fluorescence were determined using a fluorescence microscope and FCM for each group of cells. The experiments were repeated four times. The values were analyzed using the Kruskal-Wallis H-test and Bonferroni correction $\left({ }^{* *} P<0.01,{ }^{*} P<0.05\right)$

fraction. Our analysis further showed that the $\mathrm{Bcl} 2 /$ Bax ratio at the protein level in the mitochondrial fraction was significantly higher in the $\mathrm{RH}+\mathrm{ATP}$ than the $\mathrm{RH}-\Delta$ rop $18+$ ATP group $(\mathrm{C} 2=8, d f=3, P=0.017)$ (Fig. 9b, c5). These results suggested that TgROP18 protected mitochondrial depolarization and translocation of Cyt $\mathrm{C}$ from mitochondria to the cytosol. COX IV and actin were detected as controls for the mitochondrial and cytosolic fraction, respectively.

\section{TgROP18 inhibited ATP-triggered caspase activation}

The mitochondrial apoptotic pathway depends mostly on caspase-9, which in turn activates executioner caspase-3 and caspase-7 [43, 44]. Our immunoblotting results indicated that in ATP-treated SF268 cells, inactive full-length caspase- 9 was cleaved into active p35 and p37 fragments, inactive full-length caspase- 7 was cleaved into active p20 fragments, and inactive full-length caspase-3 was split into p17 fragments. In SF268 cells treated with

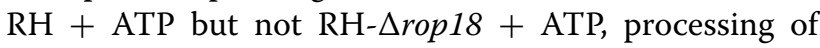
all these three procaspases was significantly inhibited. In contrast, no significant difference was detected in the levels of cleaved PARP (poly ADP-ribose polymerase) between the ATP-treated and $\mathrm{RH}+\mathrm{ATP}$ groups (Fig. 10). The results suggest that $\operatorname{TgROP} 18$ inhibits activation of these procaspases in SF268 cells.

\section{Discussion}

Based on previously reported findings, we observed variability in apoptosis regulated by type I strain RH and type II strain (NTE or ME49) in immune cells or neural cells (Additional file 6: Table S2), and found that T. gondii infection can both inhibit and induce host cell apoptosis 


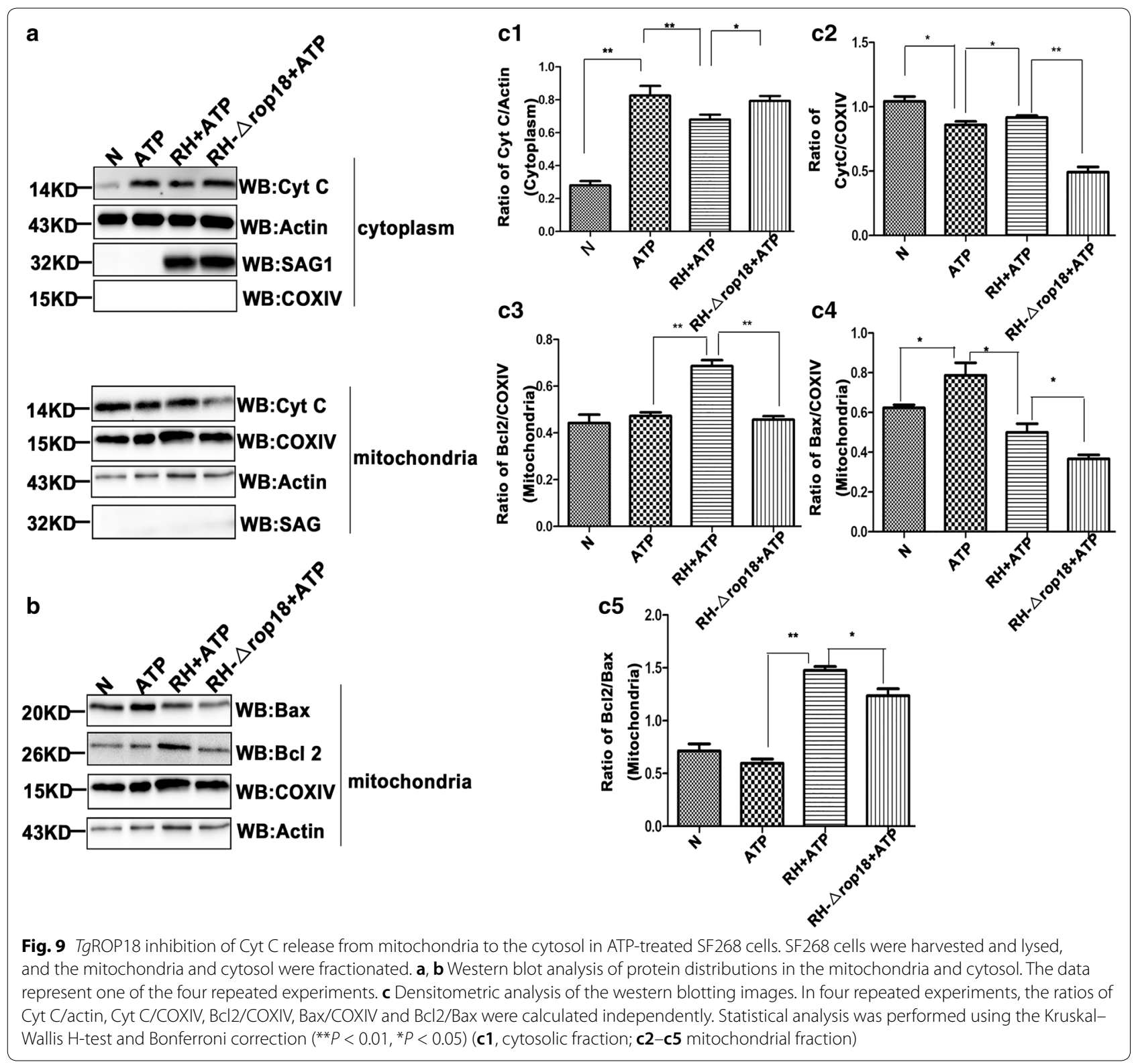

in different settings. Whether these opposite effects of $T$. gondii infection are due to variations in strain virulence and/or host cell types is not clear. To address this issue, we carried out a three by three combination study under the same conditions (Figs. 1, 2, 3). Our study employed three $T$. gondii strains with different degrees of virulence, the virulent RH-type I strain and the non-virulent ME49type II and VEG-type III strains, and three host cell lines, human SF268 neural cells, human RAW264.7 and mouse THP-1 immune cells, representing two most important hosts and two most frequently infected cell types. The results indicate that $T$. gondii infection inhibits ATPinduced apoptosis, regardless of strain virulence and host cell lines tested. This is consistent with most reports on the effects of $T$. gondii infection on apoptosis of a variety of host cells $[7,8,42,45-49]$, and it is to $T$. gondii's advantage to inhibit host cell apoptosis and keep the host cells alive [50-52].

It is thought that the induction of host immune cell apoptosis may restrict host immune response and allow T. gondii to establish infection $[49,53]$. Toxoplasma gondii infection has also been found to induce the apoptosis of mouse N2A neural cells [14] and JEG-3 choriocarcinoma cells [54]. However, it is not obvious that the induction of the apoptosis of these cells has any advantage to $T$. gondii's survival. 

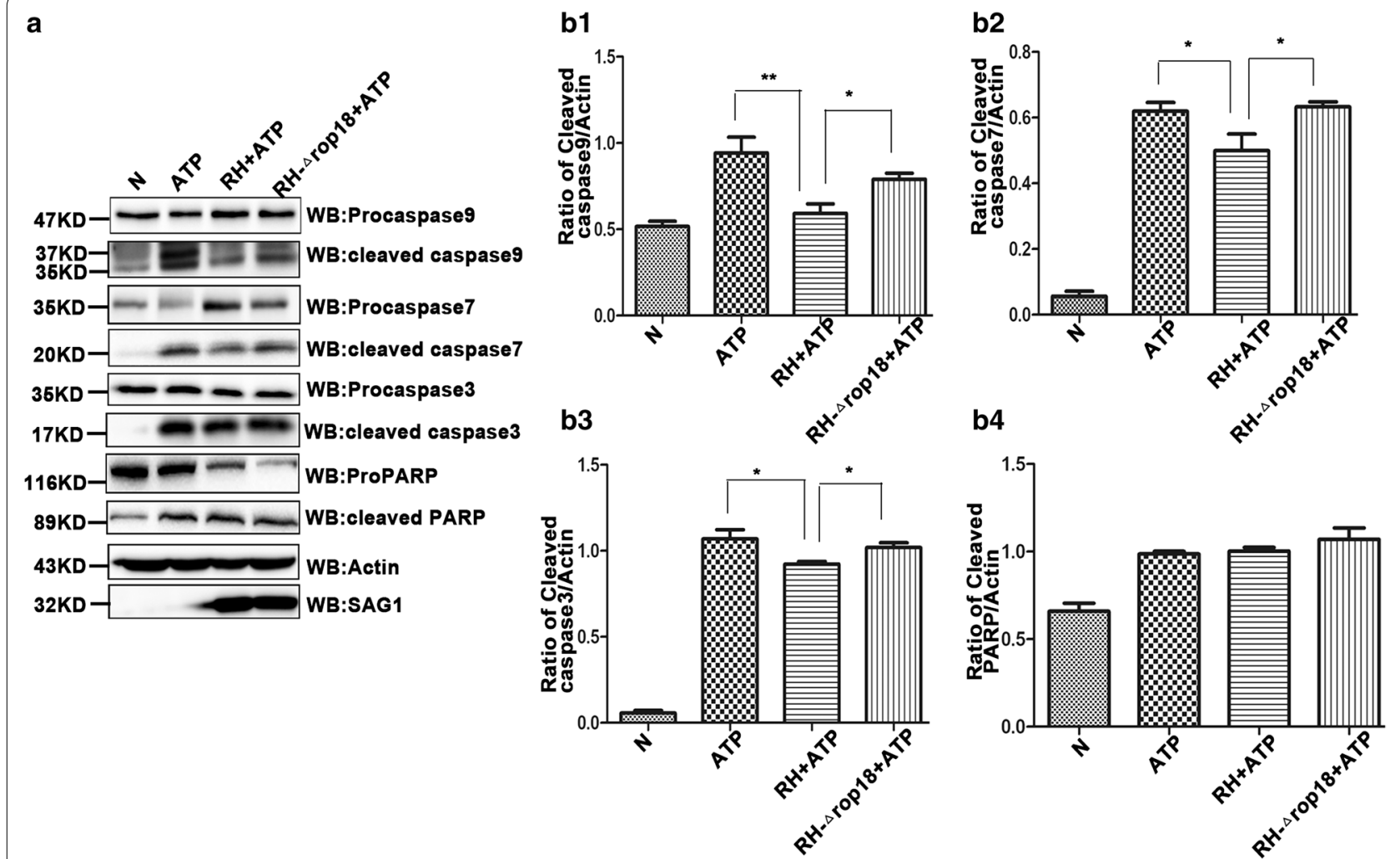

Fig. 10 TgROP18 inhibition of procaspase-3, procaspase-7 and procaspase-9 cleavage to form active caspases in ATP-treated SF268 cells. a Western blot analysis of procaspase cleavage. SF268 cells were prepared as described in Fig. 6. Cell lysates were used for western blot analysis. The antibodies used could recognize both the full-length and cleaved forms of their protein antigens. The molecular weights of the full-length and cleaved forms of the protein antigens are as follows. caspase-9: 47, 37, 35 kD; caspase-7: 35, 20 kD; caspase-3: 35, 17 kD; PARP: 116, 89 kD. Actin was used as a control, and SAG1 was used to evaluate the number of T. gondii tachyzoites, ensuring consistent numbers of host cells and tachyzoites in comparison groups. b Densitometric analysis of the western blotting images. Quantification was performed using ImageJ software, and the experiments were repeated four times for statistical analysis. The comparison the ratios of cleaved caspase-9/actin (b1), cleaved caspase-7/actin (b2), cleaved caspase-3/actin (b3), and cleaved PARP/actin (b4) between group was performed using the Kruskal-Wallis H-test and Bonferroni correction $\left(* * P<0.01,{ }^{*} P<0.05\right)$

The next questions we addressed are which virulence factor of T. gondii is involved in the inhibition of ATPinduced apoptosis and which host protein is targeted by the virulence factor of the pathogen. We investigated $\operatorname{TgROP} 18$, as it is a major virulence factor of T. gondii, and found that $\operatorname{TgROP} 18$ significantly inhibited the ATPinduced apoptosis of SF268 cells (Fig. 4) but not THP-1 and RAW264.7 cells (Additional file 5: Figure S4). The P2X1 purinergic receptor was found to form a complex with TgROP18 (Fig. 5). TgROP18 suppressed host cell apoptosis through inhibition of P2X1-mediated $\mathrm{Ca}^{2+}$ influx, but not through P2X1 degradation (Figs. 6, 7).

Then, we addressed the question of why $\operatorname{TgROP} 18$ inhibited the apoptosis of SF268 cells but not that of THP-1 and RAW264.7 cells. We found that P2X1 was expressed in SF268 cells but not in THP-1 and RAW264.7 cells (Additional file 7: Figure S5), and $\operatorname{TgROP} 18$ can bind with P2X1 to inhibit the ATP-induced cell apoptosis (Fig. 5). Owing to lack of P2X1 expression in COS7 cells, the overexpression of ROP18 in COS7 cells did not influence the cell apoptosis (Fig. 6d). Although P2X1 expression was not detected in RAW264.7 and THP-1 cells, the apoptosis of RAW264.7 can be induced by activation of the protein kinase extracellular regulated protein kinase (ERK) and mitogen-activated protein kinase (MAPK) pathway regulated by extracellular signals through P2X4 as well as P2X7 receptors [55]; and THP-1 cell apoptosis can be promoted by the increase in intracellular calcium through the P2X7 receptor [56]. Therefore, it seemed that ROP18 could only target P2X1, but not P2X4 or P2X7, to regulate host cell apoptosis. On the other hand, we also found that the P2X1 inhibitor NF449 failed to completely inhibit ATP-induced apoptosis. Thus, some pro-apoptotic receptors besides P2X1 in SF268 cells may respond to ATP stimulation to regulate the cell apoptosis.

Apoptosis can be induced by two signal transduction pathways, one termed the intrinsic pathway or the mitochondrial pathway and the other the extrinsic pathway 
$[16,57]$. Consequently, we investigated the mechanism by which $T g R O P 18$ inhibited the ATP-induced apoptosis. We found that $T g$ ROP18 inhibited mitochondrial calcium influx (Fig. 7) and depolarization (Fig. 8), the release of Cyt C from mitochondria to the cytosol (Fig. 9) and caspase maturation (Fig. 10). The first two represent the fundamental function of the P2X1 purinergic receptor, and the latter two are the key steps in the mitochondrial apoptotic pathway. The initial steps of the mitochondrial apoptotic pathway are mediated by the Bcl-2 family of proteins, including anti-apoptotic $\mathrm{Bcl}-2$ proteins and proapoptotic proteins Bax and Bak. In normal cells, $\mathrm{Bcl} 2$ and $\mathrm{Bax}$ are located predominantly in the cytosol [58], but under apoptotic conditions, they accumulate at the mitochondrial outer membrane [59]. Cyt $\mathrm{C}$ is a small hemeprotein that is found loosely associated with the mitochondrial inner membrane (MIM), where it plays a crucial role in transferring electrons [33]. Apoptotic signals such as DNA damage can increase permeabilization of the MIM, and Cyt C will be released from the MIM medium to the cytosol [60]. Whether Cyt $C$ is released into the cytosol is partly dependent on the ratio of $\mathrm{Bcl} 2 /$ Bax [60]. Our analysis demonstrated that the $\mathrm{Bcl} 2 / \mathrm{Bax}$ ratio at the protein level was significantly elevated by $T g \mathrm{ROP} 18$ in the mitochondrial fraction (Fig. 9), indicating that the release of Cyt $\mathrm{C}$ from mitochondria to the cytosol is inhibited by $\mathrm{TgROP} 18$. The results showed that TgROP18 inhibits ATP-induced apoptosis by interfering with the mitochondrial apoptotic pathway.

Although $T g$ ROP18 expression in type III strains can barely be detected, we found in this study that type III strain VEG could also inhibit host cell apoptosis. The other T. gondii factors may function in the inhibition of host cell apoptosis independently of TgROP18. It has been reported that $\operatorname{TgROP} 38$ is normally undetectable in the virulent RH strain [61]; however, it is abundant in the avirulent VEG strain at the transcriptional level, and expression of $T g R O P 38$ exerts a potent effect on the regulation of cell proliferation and apoptosis through the MAPK pathway [62]. Several other T. gondii virulence factors have been found to modulate host cell apoptosis, including T. gondii ROP38 (another rhoptry protein kinase) [62], type $2 \mathrm{C}$ protein phosphatase (PP2C) [63] and dense granule protein GRA15 [54]. Whether these and other T. gondii virulence factors also play a role in modulating ATP-induced host cell apoptosis needs to be further investigated.

\section{Conclusions}

The present findings showed that $T$. gondii infection inhibits ATP-induced host cell apoptosis, regardless of strain virulence and host cell lines. Toxoplasma gondii virulence factor TgROP18, which targeted the
C-terminus of P2X1, inhibited apoptosis mediated by P2X1. When apoptosis was induced by ATP, the P2X1 mediated $\mathrm{Ca}^{2+}$ influx was inhibited by the presence of TgROP18 in COS7 cells overexpressing both P2X1 and TgROP18. Furthermore, TgROP18 inhibited depolarization of the mitochondrial membrane, Cyt $\mathrm{C}$ translocation from the mitochondria to the cytoplasm, and ATP-triggered caspase 9, 7 and 3 activation in SF268 cells. Taken together, these findings support the conclusion that TgROP18 inhibits ATP-induced apoptosis by interfering with P2X1 function and the mitochondrial apoptotic pathway.

\section{Additional files}

Additional file 1: Table S1. Summarized information of statistical comparisons presented in the figures.

Additional file 2: Figure S1. TUNEL assay of ATP-induced apoptosis of infected SF268 cells. SF268 cells were infected with RH, ME49 or VEG strain and treated with ATP in the same way as described in Fig. 1. a1, a2 Analysis of apoptosis by fluorescence microscopy following TUNEL assay. TUNEL-positive cells were visualized as indicated by green fluorescence staining and DAPI (blue) staining to discern all cell nuclei. The percentage (\%) of TUNEL-positive cells was determined (number of TUNEL-positive cells/total number of cells $\times 100$ ). $\mathbf{b 1}$, b2 Quantification of the data in panels $\mathbf{a} 1$ and $\mathbf{a} 2$. The experiments were repeated four times. The values were analyzed using the Kruskal-Wallis $\mathrm{H}$-test and Bonferroni correction $(* * P<0.01)$.

Additional file 3: Figure S2. TUNEL assay of ATP-induced apoptosis of infected RAW264.7 cells. RAW264.7 cells were infected with the RH, ME49 or VEG strain and treated with ATP in the same way as described in Fig. 1. Data analysis and presentation were performed in the same way for the corresponding panels of Figure S1. The experiments were repeated four times. The values were analyzed using the Kruskal-Wallis $\mathrm{H}$-test and Bonferroni correction $(* * P<0.01)$.

Additional file 4: Figure S3. TUNEL assay of ATP-induced apoptosis of infected THP-1 cells. THP-1 cells were infected with the RH, ME49 or VEG strain and treated with ATP in the same way as described in Fig. 1. Data analysis and presentation were performed in the same way for the corresponding panels of Figure S1. The experiments were repeated four times. The values were analyzed using the Kruskal-Wallis $\mathrm{H}$-test and Bonferroni correction $(* * P<0.01)$

Additional file 5: Figure S4. Effect of T. gondii virulence factor ROP18 on ATP-induced apoptosis of RAW264.7 and THP-1 cells. RAW264.7 and THP-1 cells were infected with $\mathrm{RH}$ or $\mathrm{RH}-\triangle$ rop 18 tachyzoites $(\mathrm{MOI}=13$ ) or left uninfected to serve as the normal control (N) or positive control (ATP treatment). At $12 \mathrm{~h}$ post-infection, $1 \mathrm{mg} / \mathrm{ml}$ ATP was added to the cells for an additional $12 \mathrm{~h}$, except in the normal control group. a Representative flow cytometry data. b Quantification of the flow cytometry data. The percentages of apoptotic cells were separately determined for each group of cells. The experiments were repeated four times for Kruskal-Wallis H-test statistical analysis $\left({ }^{*} P<0.05,{ }^{*} P<0.01\right)$.

Additional file 6: Table S2. Summarized information for Toxoplasma gondii modulation of immune and neural cell apoptosis.

Additional file 7: Figure S5. Western blot analysis of P2X1 in SF268, RAW264.7, HFF and THP-1 cells. RAW264.7, HFF, THP-1 and SF268 cells were grown in a T25 flask to $100 \%$ confluence and then harvested and lysed. Total proteins for each sample were subjected to SDS-PAGE and western blotting analysis with P2X1 antibody. 


\begin{abstract}
Abbreviations
P2X1: purinergic receptor; TgROP18: Toxoplasma gondii rhoptry protein 18: ATP: adenosine triphosphate; Cyt C: cytochrome C; COXIV: cytochrome C oxidase IV; PARP: poly ADP-ribosepolymerases; MIM: mitochondria inner membrane.
\end{abstract}

\section{Acknowledgements}

The authors are grateful to the participants in this study and the anonymous reviewers and editors for their comments and valuable inputs.

\section{Authors' contributions}

LJZ performed the experiments, analyzed the data and wrote the manuscript. MC and SP performed FCM assays. CH generated RH- $\triangle$ rop 18, RH-ROP18GFP-Flag T. gondii. JX and SQD performed FRET. CYH was involved in study supervision and manuscript revision. HJP performed study conception and design, supervision of the research group, funding support and drafting of the manuscript. All authors read and approved the final manuscript.

\section{Funding}

This research was supported by National Key R\&D Programme of China

(2017YFD0500400), National Natural Science Foundation of China (81772217, 20180907, 81572012), Guangdong Provincial Natural Science Foundation Project (2016A030311025, 2017A030313694), Science and Technology Planning Project of Guangdong Province (2018A050506038) and Guangzhou health and medical collaborative innovation major special project (201604020011) to HJP.

\section{Availability of data and materials}

The datasets supporting the findings of this article are included within the article and its additional files.

\section{Ethics approval and consent to participate}

Not applicable.

\section{Consent for publication}

Not applicable.

\section{Competing interests}

The authors declare that they have no competing interests.

\section{Author details}

${ }^{1}$ Department of Pathogen Biology, Guangdong Provincial Key Laboratory of Tropical Disease Research, School of Public Health, Southern Medical University, Guangzhou 510515, Guangdong, People's Republic of China. 2 Department of Biological Sciences, National University of Singapore, Singapore, Singapore.

\section{Received: 6 September 2018 Accepted: 23 May 2019}

Published online: 04 June 2019

\section{References}

1. Dubey JP. History of the discovery of the life cycle of Toxoplasma gondii. Int J Parasitol. 2009;39:877-82.

2. Montoya JG, Liesenfeld O. Toxoplasmosis. Lancet. 2004;363:1965-76.

3. Ajzenberg D, Banuls AL, Su C, Dumetre A, Demar M, Carme B, et al. Genetic diversity, clonality and sexuality in Toxoplasma gondii. Int J Parasitol. 2004;34:1185-96.

4. Howe DK, Summers BC, Sibley LD. Acute virulence in mice is associated with markers on chromosome VIII in Toxoplasma gondii. Infect Immun. 1996:64:5193-8

5. Luder CG, Gross U, Lopes MF. Intracellular protozoan parasites and apoptosis: diverse strategies to modulate parasite-host interactions. Trends Parasitol. 2001;17:480-6

6. Wang T, Zhou J, Gan X, Wang H, Ding X, Chen L, et al. Toxoplasma gondii induce apoptosis of neural stem cells via endoplasmic reticulum stress pathway. Parasitology. 2014;141:988-95.
7. Hwang IY, Quan JH, Ahn MH, Ahmed HAH, Cha GH, Shin DW, et al. Toxoplasma gondii infection inhibits the mitochondrial apoptosis through induction of BCl-2 and HSP70. Parasitol Res. 2010;107:1313-21.

8. Yamada T, Tomita T, Weiss LM, Orlofsky A. Toxoplasma gondii inhibits granzyme B-mediated apoptosis by the inhibition of granzyme B function in host cells. Int J Parasitol. 2011;41:595-7.

9. Angeloni MB, Silva NM, Castro AS, Gomes AO, Silva DA, Mineo JR, et al. Apoptosis and S phase of the cell cycle in BeWo trophoblastic and HeLa cells are differentially modulated by Toxoplasma gondii strain types. Placenta. 2009;30:785-91.

10. El Hajj H, Demey E, Poncet J, Lebrun M, Wu B, Galeotti N, et al. The ROP2 family of Toxoplasma gondii rhoptry proteins: proteomic and genomic characterization and molecular modeling. Proteomics. 2006:6:5773-84.

11. Fentress SJ, Behnke MS, Dunay IR, Mashayekhi M, Rommereim LM, Fox BA, et al. Phosphorylation of immunity-related GTPases by a Toxoplasma gondii-secreted kinase promotes macrophage survival and virulence. Cell Host Microbe. 2010;8:484-95.

12. Yamamoto M, Ma JS, Mueller C, Kamiyama N, Saiga H, Kubo E, et al. ATF6beta is a host cellular target of the Toxoplasma gondii virulence factor ROP18. J Exp Med. 2011;208:1533-46.

13. Du J, An R, Chen L, Shen Y, Chen Y, Cheng L, et al. Toxoplasma gondii virulence factor ROP18 inhibits the host NF-kappaB pathway by promoting p65 degradation. J Biol Chem. 2014;289:12578-92.

14. Wan L, Gong L, Wang W, An R, Zheng M, Jiang Z, et al. T. gondii rhoptry protein ROP18 induces apoptosis of neural cells via endoplasmic reticulum stress pathway. Parasites Vectors. 2015:8:554.

15. Wu L, Wang X, Li Y, Liu Y, Su D, Fu T, et al. Toxoplasma gondii ROP18: potential to manipulate host cell mitochondrial apoptosis. Parasitol Res. 2016;115:2415-22.

16. Galluzzi L, Vitale I, Aaronson SA, Abrams JM, Adam D, Agostinis P, et al. Molecular mechanisms of cell death: recommendations of the Nomenclature Committee on Cell Death 2018. Cell Death Differ. 2018;25:486-541.

17. Gudipaty SA, Conner CM, Rosenblatt J, Montell DJ. Unconventional ways to live and die: cell death and survival in development, homeostasis, and disease. Annu Rev Cell Dev Biol. 2018;34:311-32.

18. Jorgensen I, Rayamajhi M, Miao EA. Programmed cell death as a defense against infection. Nat Rev Immunol. 2017;17:151-64.

19. Hacker G. Apoptosis in infection. Microbes Infect. 2018;20:552-9.

20. Rodrigues V, Cordeiro-da-Silva A, Laforge M, Ouaissi A, Silvestre R, Estaquier J. Modulation of mammalian apoptotic pathways by intracellular protozoan parasites. Cell Microbiol. 2012;14:325-33.

21. Friedrich A, Pechstein J, Berens C, Luhrmann A. Modulation of host cell apoptotic pathways by intracellular pathogens. Curr Opin Microbiol. 2017;35:88-99.

22. Coutinho-Silva R, Ojcius DM. Role of extracellular nucleotides in the immune response against intracellular bacteria and protozoan parasites. Microbes Infect. 2012;14:1271-7.

23. Di Virgilio F, Sarti AC, Grassi F. Modulation of innate and adaptive immunity by P2X ion channels. Curr Opin Immunol. 2018;52:51-9.

24. Idzko M, Ferrari D, Eltzschig HK. Nucleotide signalling during inflammation. Nature. 2014:509:310-7.

25. Cekic C, Linden J. Purinergic regulation of the immune system. Nat Rev mmunol. 2016:16:177-92.

26. Brasil TR, Freire-de-Lima CG, Morrot A, Veto Arnholdt AC. HostToxoplasma gondii coadaptation leads to fine tuning of the immune response. Front Immunol. 2017:8:1080.

27. Coddou C, Yan Z, Obsil T, Huidobro-Toro JP, Stojilkovic SS. Activation and regulation of purinergic $\mathrm{P} 2 \mathrm{X}$ receptor channels. Pharmacol Rev. 2011;63:641-83.

28. North RA. P2X receptors: a third major class of ligand-gated ion channels. Ciba Found Symp. 1996;198:91-105

29. Roberts JA, Bottrill AR, Mistry S, Evans RJ. Mass spectrometry analysis of human P2X1 receptors; insight into phosphorylation, modelling and conformational changes. J Neurochem. 2012;123:725-35.

30. Gan M, Moussaud S, Jiang P, McLean PJ. Extracellular ATP induces intracellular alpha-synuclein accumulation via P2X1 receptor-mediated lysosomal dysfunction. Neurobiol Aging. 2015;36:1209-20. 
31. Woehrle T, Yip L, Elkhal A, Sumi Y, Chen Y, Yao Y, et al. Pannexin-1 hemichannel-mediated ATP release together with $\mathrm{P} 2 \mathrm{X} 1$ and $\mathrm{P} 2 \mathrm{X} 4$ receptors regulate $T$-cell activation at the immune synapse. Blood. 2010;1 16:3475-84.

32. Sim JA, Park CK, Oh SB, Evans RJ, North RA. P2X1 and P2X4 receptor currents in mouse macrophages. Br J Pharmacol. 2007;152:1283-90.

33. Zhu Y, Li M, Wang X, Jin H, Liu S, Xu J, et al. Caspase cleavage of cytochrome $\mathrm{c} 1$ disrupts mitochondrial function and enhances cytochrome c release. Cell Res. 2012;22:127-41.

34. Park EK, Jung HS, Yang HI, Yoo MC, Kim C, Kim KS. Optimized THP-1 differentiation is required for the detection of responses to weak stimuli. Inflamm Res. 2007;56:45-50.

35. He C, Kong L, Zhou L, Xia J, Wei H, Liu M, et al. Host cell vimentin restrains Toxoplasma gondii invasion and phosphorylation of vimentin is partially regulated by interaction with TgROP18. Int J Biol Sci. 2017;13:1126-37.

36. Elangovan M, Wallrabe $H$, Chen $Y$, Day RN, Barroso M, Periasamy A. Characterization of one- and two-photon excitation fluorescence resonance energy transfer microscopy. Methods. 2003;29:58-73.

37. Foltman M, Sanchez-Diaz A. Studying protein-protein interactions in budding yeast using co-immunoprecipitation. Methods Mol Biol. 2016;1369:239-56.

38. De Biasi S, Gibellini L, Cossarizza A. Uncompensated polychromatic analysis of mitochondrial membrane potential using JC-1 and multilaser excitation. Curr Protoc Cytom. 2015;72:3.1-11.

39. Kerppola TK. Bimolecular fluorescence complementation (BiFC) analysis as a probe of protein interactions in living cells. Annu Rev Biophys. 2008;37:465-87.

40. Xia J, Kong L, Zhou LJ, Wu SZ, Yao LJ, He C, et al. Genome-wide bimolecular fluorescence complementation-based proteomic analysis of Toxoplasma gondii ROP18's human interactome shows its key role in regulation of cell immunity and apoptosis. Front Immunol. 2018:9:61.

41. Wen H, Evans RJ. Contribution of the intracellular C terminal domain to regulation of human $\mathrm{P} 2 \mathrm{X} 1$ receptors for ATP by phorbol ester and Gq coupled mGlu(1alpha) receptors. Eur J Pharmacol. 2011;654:155-9.

42. Hippe D, Lytovchenko O, Schmitz I, Luder CG. Fas/CD95-mediated apoptosis of type II cells is blocked by Toxoplasma gondii primarily via interference with the mitochondrial amplification loop. Infect Immun. 2008;76:2905-12.

43. Thornberry NA, Lazebnik Y. Caspases: enemies within. Science. 1998;281:1312-6.

44. Wu CC, Bratton SB. Regulation of the intrinsic apoptosis pathway by reactive oxygen species. Antioxid Redox Signal. 2013;19:546-58.

45. Contreras-Ochoa CO, Lagunas-Martinez A, Belkind-Gerson J, Diaz-Chavez J, Correa D. Toxoplasma gondii invasion and replication within neonate mouse astrocytes and changes in apoptosis related molecules. Exp Parasitol. 2013;134:256-65.

46. Goebel S, Gross U, Luder CG. Inhibition of host cell apoptosis by Toxoplasma gondii is accompanied by reduced activation of the caspase cascade and alterations of poly(ADP-ribose) polymerase expression. J Cell Sci. 2001;114:3495-505.

47. Keller P, Schaumburg F, Fischer SF, Hacker G, Gross U, Luder CG. Direct inhibition of cytochrome $c$-induced caspase activation in vitro by Toxoplasma gondii reveals novel mechanisms of interference with host cell apoptosis. FEMS Microbiol Lett. 2006;258:312-9.

48. Quan JH, Cha GH, Zhou W, Chu JQ, Nishikawa Y, Lee YH. Involvement of PI 3 kinase/Akt-dependent Bad phosphorylation in Toxoplasma gondiimediated inhibition of host cell apoptosis. Exp Parasitol. 2013;133:462-71.
49. Luder CG, Gross U. Apoptosis and its modulation during infection with Toxoplasma gondii: molecular mechanisms and role in pathogenesis. Curr Top Microbiol Immunol. 2005;289:219-37.

50. Gavrilescu LC, Denkers EY. IFN-gamma overproduction and high level apoptosis are associated with high but not low virulence Toxoplasma gondii infection. J Immunol. 2001;167:902-9.

51. Liesenfeld O, Kosek JC, Suzuki Y. Gamma interferon induces Fas-dependent apoptosis of Peyer's patch T cells in mice following peroral infection with Toxoplasma gondii. Infect Immun. 1997;65:4682-9.

52. Mordue DG, Monroy F, La Regina M, Dinarello CA, Sibley LD. Acute toxoplasmosis leads to lethal overproduction of Th1 cytokines. J Immunol. 2001;167:4574-84.

53. Rodrigues V, Cordeiro-da-Silva A, Laforge M, Ouaissi A, Silvestre R, Estaquier J. Modulation of host programmed cell death pathways by the intracellular protozoan parasite. Cell Microbiol. 2015;14:325-33.

54. Wei W, Zhang F, Chen H, Tang Y, Xing T, Luo Q, et al. Toxoplasma gondii dense granule protein 15 induces apoptosis in choriocarcinoma JEG-3 cells through endoplasmic reticulum stress. Parasites Vectors. 2018;11:251.

55. Kawano A, Tsukimoto M, Noguchi T, Hotta N, Harada H, Takenouchi $T$, et al. Involvement of $\mathrm{P} 2 \mathrm{X} 4$ receptor in $\mathrm{P} 2 \mathrm{X} 7$ receptor-dependent cell death of mouse macrophages. Biochem Biophys Res Commun. 2012;419:374-80

56. Wang W, Xiao J, Adachi M, Liu Z, Zhou J. 4-aminopyridine induces apoptosis of human acute myeloid leukemia cells via increasing [Ca2+]i through P2X7 receptor pathway. Cell Physiol Biochem. 2011;28:199-208.

57. Nagata S. Apoptosis and clearance of apoptotic cells. Annu Rev Immunol. 2018;36:489-517.

58. Kluck RM, Bossy-Wetzel E, Green DR, Newmeyer DD. The release of cytochrome $\mathrm{c}$ from mitochondria: a primary site for $\mathrm{BCl}-2$ regulation of apoptosis. Science. 1997;275:1132-6.

59. Birkinshaw RW, Czabotar PE. The BCL-2 family of proteins and mitochondrial outer membrane permeabilisation. Semin Cell Dev Biol. 2017;72:152-62.

60. Chien CT, Chang TC, Tsai CY, Shyue SK, Lai MK. Adenovirus-mediated bcl-2 gene transfer inhibits renal ischemia/reperfusion induced tubular oxidative stress and apoptosis. Am J Transplant. 2005;5:1194-203.

61. Saeij JP, Boyle JP, Coller S, Taylor S, Sibley LD, Brooke-Powell ET, et al. Polymorphic secreted kinases are key virulence factors in toxoplasmosis. Science. 2006;314:1780-3.

62. Peixoto L, Chen F, Harb OS, Davis PH, Beiting DP, Brownback CS, et al. Integrative genomic approaches highlight a family of parasite-specific kinases that regulate host responses. Cell Host Microbe. 2010;8:208-18.

63. Gao XJ, Feng JX, Zhu S, Liu XH, TardieuX I, Liu LX. Protein phosphatase $2 \mathrm{C}$ of Toxoplasma gondii interacts with human SSRP1 and negatively regulates cell apoptosis. Biomed Environ Sci. 2014;27:883-93.

\section{Publisher's Note}

Springer Nature remains neutral with regard to jurisdictional claims in published maps and institutional affiliations.

Ready to submit your research? Choose BMC and benefit from

- fast, convenient online submission

- thorough peer review by experienced researchers in your field

- rapid publication on acceptance

- support for research data, including large and complex data types

- gold Open Access which fosters wider collaboration and increased citations

- maximum visibility for your research: over $100 \mathrm{M}$ website views per year

At BMC, research is always in progress.

Learn more biomedcentral.com/submissions 